Canadian Science Publishing

Journal of Unmanned Vehicle Systems Revue des systèmes de véhicules télécommandés

\title{
Design and field experimentation of a robotic system for tailings characterization
}

\begin{tabular}{|r|l|}
\hline Journal: & Journal of Unmanned Vehicle Systems \\
\hline Manuscript ID & juvs-2015-0034.R1 \\
\hline Manuscript Type: & Article \\
\hline Date Submitted by the Author: & 15 -Jan-2016 \\
\hline Complete List of Authors: & $\begin{array}{l}\text { Olmedo, Nicolas; University of Alberta, Mechanical Engineering } \\
\text { Lipsett, Michael; University of Alberta, Mechanical Engineering }\end{array}$ \\
\hline Keyword: & mobile robotics, field robotics, terramechanics, oil sands, tailings \\
\hline
\end{tabular}




\title{
Design and field experimentation of a robotic system for tailings characterization
}

\author{
Nicolas A. Olmedo \\ Department of Mechanical Engineering \\ University of Alberta \\ Edmonton Alberta, Canada \\ olmedo@ualberta.ca
}

\author{
Michael G. Lipsett \\ Department of Mechanical Engineering \\ University of Alberta \\ Edmonton Alberta, Canada \\ mlipsett@ualberta.ca
}

\begin{abstract}
There is an ongoing requirement to conduct ground surveys of engineered mine tailings deposits to monitor dewatering performance and consolidation prior to completing reclamation work. The deposit variability can make such surveys hazardous for humans. A rover is described that has been developed and deployed for characterizing reclaimed soil regions. This paper presents the functional requirements for unmanned ground vehicles used in this application, including the need for low-risk and timely subsurface sampling and terrain parameter estimations on highly uncertain terrains. Developments of the field-ready prototype wheeled rover are summarized, including tooling; and field tests are described in an industrial site at an Athabasca oil sands facility. Experiments on tailings treatment cells showed the feasibility of the sampling technologies and parameter estimation methods based on classical terramechanics models. The rover capabilities were further demonstrated by collecting samples from production treatment cells and estimating the cohesion and internal friction angle of tailings sand used in fluid containment dykes. The limitations of the current system helped identify future work for the design and development of new mobile robot systems for tailings characterization.
\end{abstract}




\section{Introduction}

Robotic systems are playing increasingly important roles in the field of environmental monitoring of industrial sites. Industrial operations that affect soil properties require continuous and rigorous monitoring of soil characteristics. One example of this is oil sands bitumen production processes in northern Alberta, Canada. It is currently estimated that there are 170 billion barrels of recoverable oil in Canadian oil sands deposits (Alberta-Energy, 2014c). The oil sands industry produced 1.9 million barrels of oil per day in 2012 and is expected to double that production rate in the next decade (Alberta-Energy, 2014a). In surface mining methods, the water-based bitumen extraction process generates fluid tailings, comprising sand, silts, clays, process-affected water, and residual bitumen. Tailings from these plants are deposited into impoundments where the sand forms an earth dam that holds the fine solids suspended in water. The fines slowly settle and form water-saturated layers (Dusseault and Don Scott, 1983). These partially consolidated fine solids are called Mature Fine Tailings (MFT). With approximately 30-35 wt\% solids (Allen, 2008), MFT has a consistency similar to yogurt and is not trafficable. For this reason, MFT cannot be reclaimed without further treatment. To further densify and consolidate the material, MFT is mixed with reagents (and sometimes tailings sand to provide a weight-bearing charge) (Matthews et al., 2002). The resulting material called composite or consolidated tailings (CT) is moved into permanent tailings areas. An alternative method is to add anionic flocculants to MFT and partially dry the resulting paste (Fig. 1).

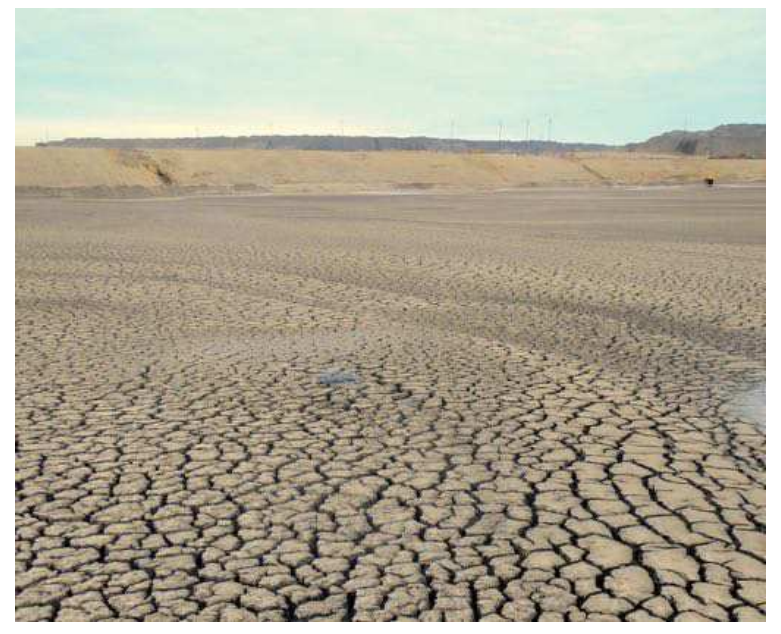

Figure 1: Soft Tailings Drying Production Cell, Athabasca Oil Sands, Alberta.

In most jurisdictions, land used for industrial operations such as mining must be returned to its equivalent natural state once industrial activities are completed (Alberta-Energy, 2014b). The challenge is that often the time scale for reclamation and closure of a site is long; and, until the regional regulatory authority grants a closure certificate, the terrestrial, aquatic, and atmospheric condition must be monitored.

An important example in Canada is reclamation of tailings impoundments. Reclamation work can only be done once fluid tailings (a mixture of water and fine solids) have drained enough water and gained enough bearing strength to support equipment and workers.

Currently, there are over 840 million cubic meters of fluid tailings stored in approximately 170 square kilometers of impoundments on oil sands sites in Northern Alberta (Alberta-Energy-Regulator, 2010). These impoundments are water saturated, and MFT sludge in the bottom of these water-capped ponds consolidates very slowly, reaching only the consistency of thick mud. To deal with the increasing volume of tailings and the extensive land area required to support the operations, companies have developed new tailings treatment processes to produce consolidated tailings that release water and gain shear strength over time. Two main processes have been implemented: coagulant addition, and flocculant addition. Coagulant addition entails mixing gypsum with MFT, and a large volume of sand is added to create a gravity load to press water out of 
the mixture. Flocculant addition involves adding a polymer to MFT and placing the mixture into a cell to allow dewatering to occur followed by drying. Both processes require ongoing monitoring. The Alberta Energy Regulator has published legislation to regulate tailings management (Alberta-Energy-Regulator, 2009). Measurements of soil properties and sampling are required to identify hazards, understand sedimentation processes, minimize long term storage of tailings, and facilitate progressive reclamation (Lipsett and Dwyer, 2009; Alberta-Energy-Regulator, 2009).

Currently the characterization of tailings deposits is done using manual geotechnical sampling and measurement campaigns (Beier et al., 2013). These campaigns are costly and are limited to very few locations that have been made accessible to workers by installing floating docks on tailings treatment cells, or by employing large amphibious barges (Fig. 2). Equipment sinking and injuries to workers are possible risks due to variability in the consistency of the deposits and the nature of the sampling procedures. Due to these limitations and risks, manual surveys do not provide an adequate and timely characterization and mapping of the deposits.

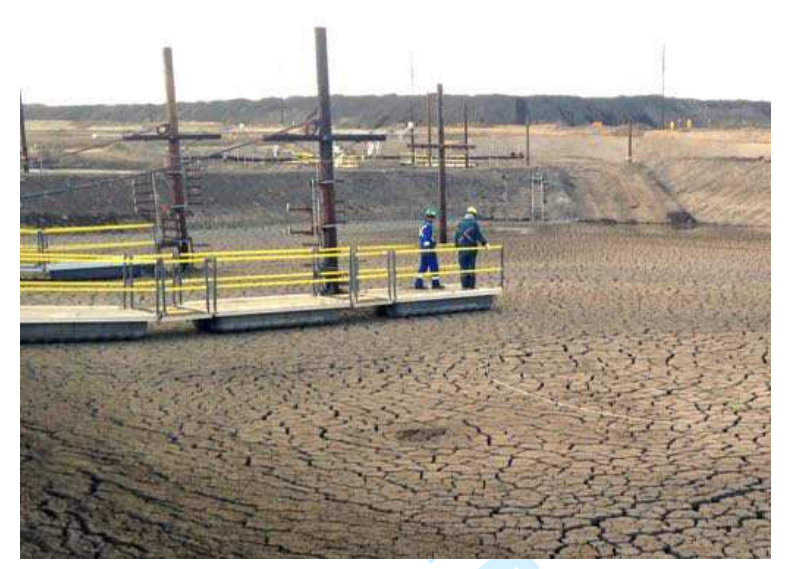

Figure 2: Floating dock on a tailings treatment test cell with two workers collecting samples.

Unmanned Ground Vehicles (UGVs) can be integrated as part of ground surveys of oil sands tailings deposits. Robotic systems can overcome many of the limitations of manual surveys and provide additional benefits: (i) minimize risk to workers, (ii) characterize locations that are not accessible to manual campaigns, (iii) estimate soil properties in a timely manner, (iv) collect samples from deep deposits, (v) assess trafficability of the terrain, (vi) identify hazards and their location, (vii) minimize risk \& cost of a survey, and (viii) generate reports of soil shear strength and fines capture rates for regulatory compliance (Lipsett and Dwyer, 2009). The potential value of geotechnical surveys with robotic systems is a strong motivation for the development of new technologies that can characterize key soil properties and can collect soil samples.

A team at the University of Alberta's Integrated Reliable Oil Sands Systems Laboratory is developing UGVs for tailings characterization in collaboration with companies that operate oil sands tailings facilities. The goal of this program is to produce a robust field robotic system for navigation, sampling, and geotechnical measurement, and to evaluate its capability through controlled laboratory trials and field experiments. In accordance with this goal, specific objectives are as follows: (i) detail the robotic system's functionality requirements for characterizing the oil sands tailings, (ii) develop a mobile robot prototype, (iii) conduct field trials on an industrial site, (iv) analyze the results and discuss the feasibility of the proposed system , and (v) provide recommendations based on the results and analysis of the field trials.

The present work discusses the development and field trials of the first field-ready Rover for Tailings Characterization (RTC-I) (Fig. 3), in five sections: a discussion of related work and a summary of developments of previous prototypes; functional specifications for characterizing tailings; description of the development of RTC-I; description \& discussion of a set of field trials performed in an industrial setting; and recommen- 
dations are provided \& future work is identified.

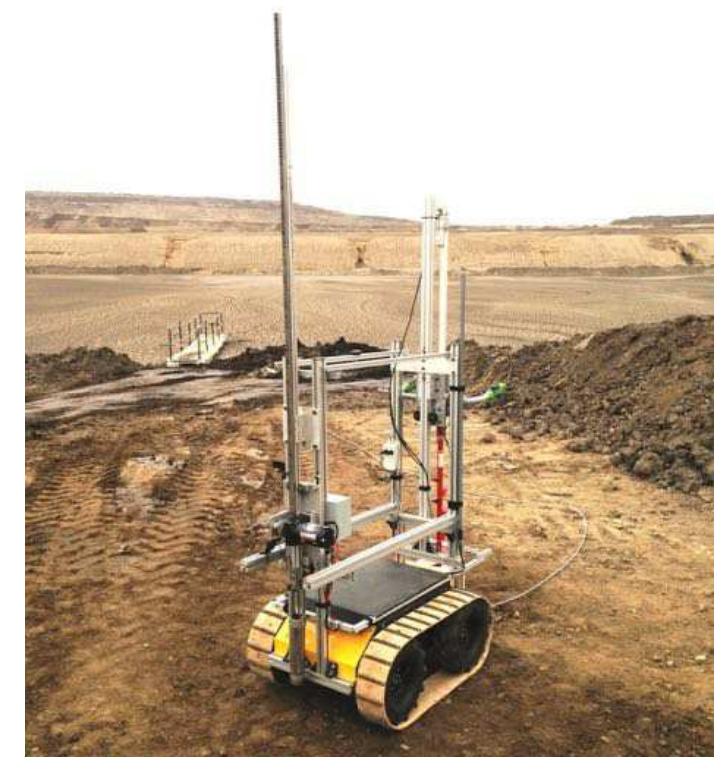

Figure 3: Robotic system for tailings characterization.

\section{Related work}

This section presents related work focused on the techniques, methods and technologies used to characterize environments using mobile robots, summarizes the group's previous developments of mobile platforms and geotechnical tooling for monitoring soft tailings deposits, and discusses the limitations of current solutions.

\subsection{Recent research on environmental characterization using UGVs}

Remote sensing with UGVs has been applied to rugged environments. Freitas et al. developed an Environmental Hybrid Robot that has been used to monitor the Amazon rain forest (Freitas et al., 2011). The robot was designed to operate in various field conditions such as sand, water, marshes, and swamps. Its main objectives were to obtain water samples and insect larvae samples, measure water parameters, and detect combustible gases (Freitas et al., 2011). The success of this platform demonstrated the value of introducing robotic systems to perform work in areas inaccessible to workers.

Lipsett et al. discussed mission concepts utilizing mobile platforms, both aerial and ground-based, for condition monitoring of industrial installations (Lipsett et al., 2014). The study suggested that a combination of platforms can be commissioned as a remote monitoring solution that can achieve higher timeliness, accuracy and number of collected features of interest than current methods of information gathering. It was also noted that the robotic systems used for inspection and fault detection must have higher reliability than the overall system and that risk assessment methods, such as Fault Modes and Effects Analysis (FMEA), are well suited to mobile field robotics (Lipsett et al., 2014).

Rock and regolith sampling technologies have been advanced for applications in space exploration using mobile robots. Wettergreen et al. developed and field tested a Lunar rover with a regolith core drill system for the surveying of resources in polar craters (Wettergreen et al., 2010). The Sample Acquisition/Sample Processing and Handling subsystem of Mars Science Laboratory was designed to study the geological history of Mars (Anderson et al., 2012). It has been successful in conducting the first extraterrestrial drilling of rocks (Helmick et al., 2013). Sampling of soft subsurface watered soils still remains a challenge. 
Unmanned systems have been proposed to estimate soil properties of unknown environments (Tagnemma and Dubowsky, 2004). Terramechanics models have been utilized to relate loads on a wheel of a vehicle to its motion and key soil properties such as the cohesion stress, $c$, and the internal friction angle, $\phi$ (Bekker, 1969). The shear strength of the soil can be computed from these soil properties and can be used to assess the trafficability of an environment. Iagnemma et al., and Yoshida et al. have used Bekker's terramechanics models to estimate the cohesion stress and the internal friction angle of soils using instrumented mobile platforms for space exploration applications (Iagnemma et al., 2002; Yoshida, 2006). Other studies have focused on the simulation and empirical work on test beds to develop least-square methods for online soil parameter estimation (Yoshida, 2006). Terrestrial rovers can be developed and instrumented to use similar techniques to aid in the geotechnical surveys of industrial sites.

\subsection{Developments of mobile platforms and tooling for studies of tailings deposits}

Our group has conducted preliminary work to design and instrument mobile platforms and specialized geotechnical tooling. A lightweight gas powered mobile robot was retrofitted to conduct wheel-soil interaction studies in a laboratory setting (Olmedo and Lipsett, 2012) (Fig. 4). The objective of these studies was to estimate the cohesion stress and internal friction angle of dry sand using an instrumented mobile platform analogous to the mobile equipment used in an industrial environment. Measurements of linear velocity, angular velocity, sinkage, and torque of the front wheels were obtained as the robot moved through sand. A linearized slip-based terramechanics model was used to estimate the soil parameters, with favourable results. There were challenges with the controllability of the hydraulic motors, the vibration of the internal combustion engine, and the high maintenance requirements of the hydraulic system.

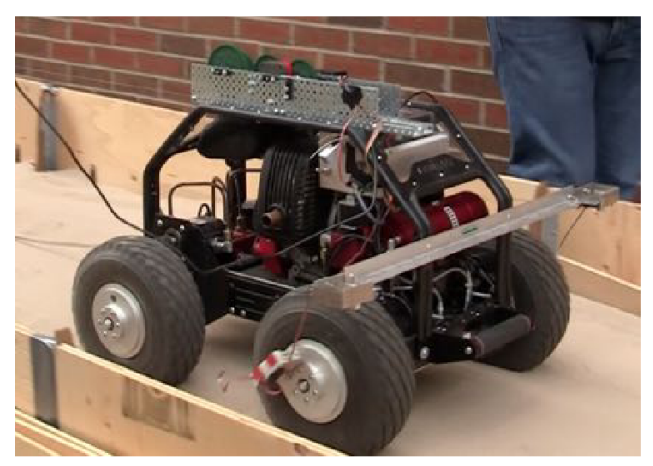

Figure 4: Gas powered mobile robot.

A tooling package was then developed for subsurface soil sampling (Fig. 5a). The soil sampler was designed to be mounted on the gas-powered rover and capture material from tailings deposits with shear strengths up to $10 \mathrm{kPa}$. The system used a vertical hydraulic actuator to push a container through the soil and capture material up to $50 \mathrm{~cm}$ deep. Several container configurations were required to manage the uncertainty of the shear strength and cohesive stress of the deposit. The tool was designed to be automated to capture multiple samples using a rotary magazine to switch between containers. A key limitation of this system is that a layer of high strength material on the surface of a tailings deposit, such as a crust, would reduce its functionality.

An electric mobile robot was prototyped to overcome the challenges of the gas powered rover prototype discussed previously (Fig. 5b). Electric actuators improved the controllability of the system, produced less vibration and required less maintenance. The electric rover was instrumented to conduct terramechanics studies, similarly to the gas powered rover. The robot was also equipped with a cone penetrometer and a soft soil sampler mounted on linear electric-motor actuators. The geotechnical tools were powered by on-board electronics and teleoperated using a wireless controller (although capability was included for autonomous tool operation). The system was tested in laboratory settings and outdoor environments. Soft soil samples were collected up to $35 \mathrm{~cm}$ deep. The mobile platform is limited to traverse deposits with a bearing strength 
greater than $35 \mathrm{kPa}$, due to the mass of the platform and payload, and the size of the tires. This is adequate for some tailings structures, noting that other types of structure would require much lower ground-pressures, or even a floating platform for cases where there is no effective shear strength.

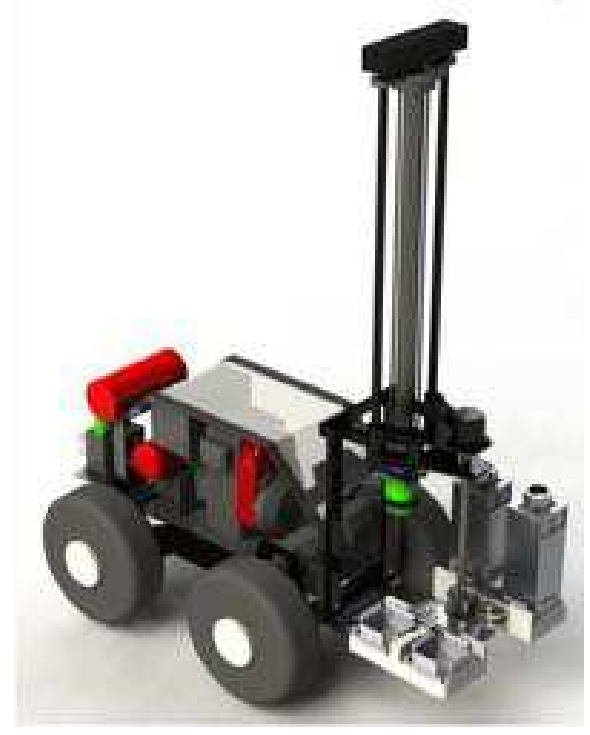

(a)

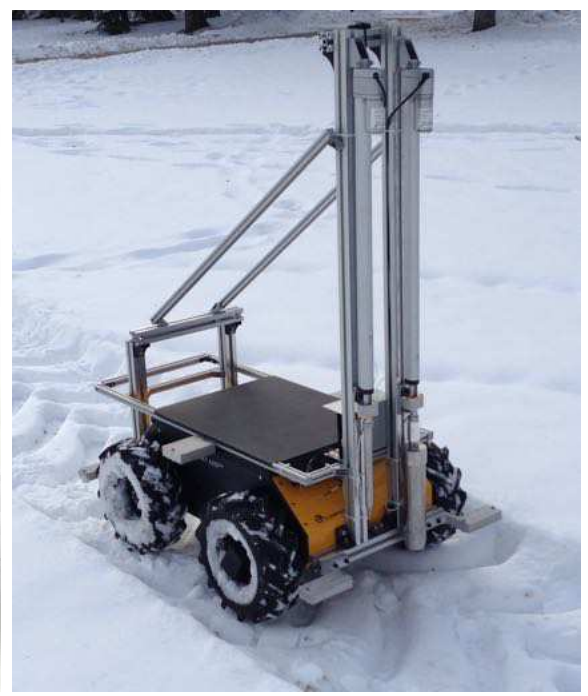

(b)

Figure 5: (a) Soft soil sampler concept. (b) Electric platform with cone penetrometer and soil sampler.

The gas powered rover and the electric platform were successful proofs-of-concept of UGVs instrumented for characterizing the surface of a deposit through wheel-soil interaction experiments and geotechnical tooling. The success and limitations of these systems has spurred the development of improved technologies and their evaluation in real industrial settings.

\section{$3 \quad$ Functional specifications for characterizing oil sands tailings}

Geotechnical surveys are conducted on tailings treatment cells to monitor the dewatering process. Recently poured, flocculated MFT is water-saturated and has no bearing strength. As water drains, consolidation occurs, and percolation and evaporation result in a crust forming on the surface (Fig. 6). This crust can be up to $45 \mathrm{~cm}$ deep and have a bearing strength higher than $30 \mathrm{kPa}$, enough to support a person or low-groundpressure equipment. The material under the crust does not readily consolidate and its bearing strength can remain very low. Without large and expensive amphibious equipment, robotic systems are the only option to conduct soil sampling and surface soil characterization on these tailings treatment cells.

Soil sampling would allow oil sands tailings operators and researchers to understand and predict consolidation processes by analyzing solids concentration, water chemistry, bitumen content, and mineral content. Mineral content is especially valuable for understanding the relationship between mineral characteristics and reagent addition. Fines abundance, cation exchange activity, and particle size distribution are all important. Decreasing particle size means increasing surface area, in a squared relationship. Knowing that there is a large amount of fines is important for tailings treatment, with the reasonable assumption that with increasing surface area more reagent will be needed for effective flocculation to promote dewatering and strengthening of the resulting soil. Surface soil characterization would allow estimation of key soil parameters, as well as establishment of relationships with terrain properties such as shear strength for trafficability assessment, which is needed to know when the soil is suitable for the next stage of reclamation where equipment cover the soft tailings with sand and topsoil. As well, understanding the tailings properties can allow better mobility control of the robotic system as well as the identification of hazards such as soft spots where a rover 
might sink. The requirements for soil sampling and surface soil characterization are summarized based on discussions with oil sands tailings operators and researchers.

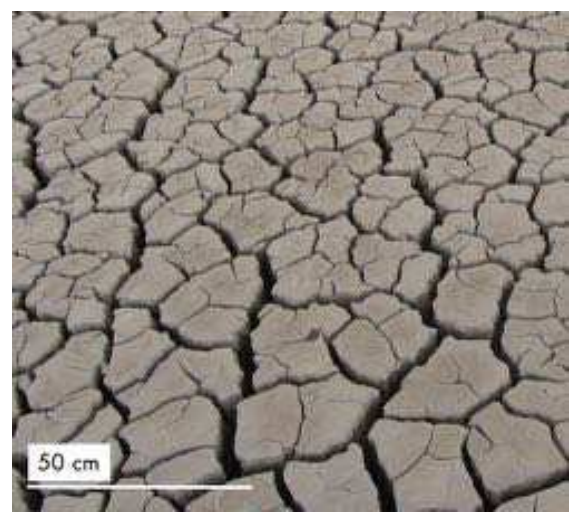

Figure 6: High strength crust on top of a tailings deposit.

\subsection{Subsurface sampling}

A teleoperated mobile robot is required to collect tailings samples far from the edge of a treatment cell. For proof-of-concept trials, a distance of 10 metres was deemed to be representative. The robot must be able to maneuver on crusts with bearing strengths as low as $20 \mathrm{kPa}$ and must have a cable tether that can be used to retrieve it in case of excessive sinkage. Subsurface samples must be collected from a minimum of $1.5 \mathrm{~m}$ below the surface and have a volume larger than $400 \mathrm{cubic} \mathrm{cm}$. The operator must receive sensory feedback of the sampling process. Undisturbed surface samples can also be collected but these samples are not a priority.

\subsection{Surface characterization}

A teleoperated mobile robot is required to traverse soft ground and estimate properties of the deposit surface. The instrumentation required to accomplish this task will depend on the method chosen to estimate soil properties. A set of samples can be collected, but the spacing of samples will make the resulting map quite uncertain.

Undisturbed surface samples can be used to validate material properties estimates from other instruments such as a Fourier Transform Infrared Radiometer (FTIR) or hyper-spectral cameras, which can take a set of measurements over the entire surface of interest with reasonable resolution, related to estimating water content, hydrocarbon abundance, and mineral abundance and properties. These remote sensing approaches, however, provide no direct geotechnical shear strength measurements.

Soil properties can be estimated directly by exploring the vehicle-ground interactions. Primary sensors include encoders and torque transducers on the wheel shafts to measure speed and loads. Cohesive stress and internal friction angle are the required parameters to estimate. These parameters can be used to compute the maximum shear stress before failure using Coulomb's equation:

$$
\tau_{\max }=c+\sigma \tan \phi
$$

where $c$ is the cohesion stress, $\sigma$ is the normal stress, and $\phi$ is the internal friction angle. Terrain trafficability assessment and hazard identification can be conducted with accurate estimates of the shear strength of the deposit. Online soil parameter estimation and hazard detection can also be implemented. The next section reviews the existing soil parameter estimation method based on wheel-soil interactions. 


\subsubsection{Terramechanics modeling}

The wheel-soil interaction is modeled using Bekker's classical slip-based terramechanics models (Bekker, 1969). This formulation has been used extensively, and is currently being used on simulation environments for planetary rovers (Zhou et al., 2014).

The states and loading of a rigid wheel traversing deformable terrain are shown in Figure 7 , where $W, D P$, and $T$ are the normal load, draw-bar pull, and torque applied to the wheel respectively. The states of the wheel are the wheel's angular speed $\omega$, ground speed $v$, and sinkage $z$. The contact area is defined by the front and rear contact angles $\theta_{1}$ and $\theta_{2}$. The normal and shear stresses are shown by $\sigma$ and $\tau$ and the angle of maximum stress is given by $\theta_{m}$. In this formulation, the shear and normal stresses are related to the

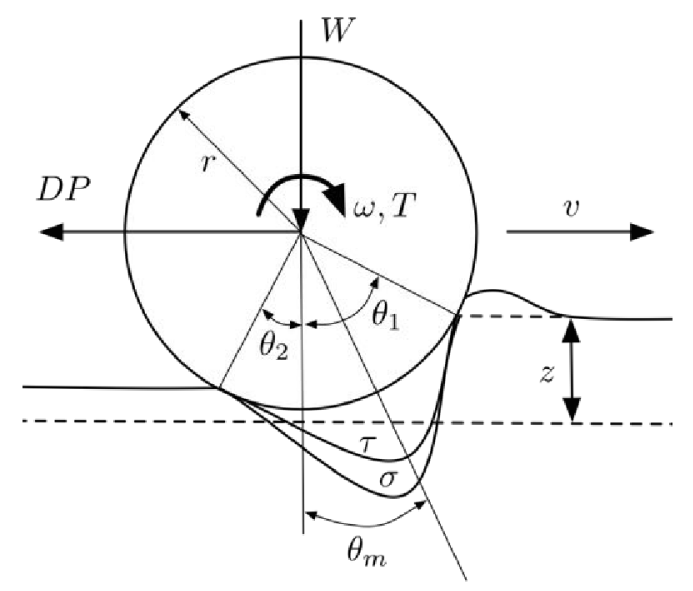

Figure 7: Wheel-soil interaction.

terrain properties using Equations 2 and 3 where $\theta$ is the angular displacement around the wheel, $k$ is the shear displacement under the wheel, and $k_{c}, k_{\phi}$ and $n$ are soil parameters. The terrain is assumed to be homogeneous and isotropic within the volume of interest.

$$
\begin{gathered}
\tau(\theta)=(c+\sigma(\theta) \tan \phi)\left(1-e^{\left(-r / k\left(\theta_{1}-\theta-(1-s)\left(\sin \theta_{1}-\sin \theta\right)\right)\right)}\right) \\
\sigma(\theta)=\left(\frac{k c}{b}+k_{\phi}\right) z(\theta)^{n}
\end{gathered}
$$

The slip ratio $s$ can be calculated from $\omega, v$, and the wheel radius $r$, using

$$
s= \begin{cases}(r \omega-v) / r \omega & r \omega>v \text { accelerating } \\ (r \omega-v) / v & r \omega<v \text { decelerating }\end{cases}
$$

Linearized stress distributions have been proposed to estimate the loading expected on the wheel during quasi-static motion (Iagnemma et al., 2002). The maximum normal and shear stresses, $\sigma_{m}$ and $\tau_{m}$, are assumed to occur at $\theta_{m}$, midway between the front and rear contact angles. The rear contact angle is assumed to be zero, for in practice it is very small. Previous work has used this assumption for a range of soil parameters (Tagnemma and Dubowsky, 2004). By assuming linear stress distributions, the normal force and torque on the wheel can be related to the wheel's motion, loading, and soil properties using Equations 5 and 6 , where $b$ is the wheel width, and $\tau_{m}$ can be calculated from Equation 7 .

$$
\begin{aligned}
W & =\frac{r b\left(\sigma_{m}\left(-\theta_{m} \cos \left(\theta_{1}\right)+\theta_{1} \cos \left(\theta_{m}\right)-\theta_{1}\right)-\tau_{m}\left(\theta_{m} \sin \left(\theta_{1}\right)-\theta_{1} \sin \left(\theta_{m}\right)\right)\right)}{\theta_{m}\left(\theta_{1}-\theta_{m}\right)} \\
& +\frac{r b\left(-c\left(\theta_{1} \sin \left(\theta_{m}\right)-\theta_{m} \sin \left(\theta_{m}\right)-\theta_{m} \theta_{1}+\theta_{m}{ }^{2}\right)\right)}{\theta_{m}\left(\theta_{1}-\theta_{m}\right)}
\end{aligned}
$$




$$
\begin{gathered}
T=1 / 2 r^{2} b\left(\tau_{m} \theta_{1}+c \theta_{m}\right) \\
\tau_{m}=\left(c+\sigma_{m} \tan (\phi)\right)\left(1-\mathrm{e}^{-(r / k)\left(\theta_{1}-\theta_{m}-(1-s)\left(\sin \left(\theta_{1}\right)-\sin \left(\theta_{m}\right)\right)\right)}\right)
\end{gathered}
$$

By manipulating Equations 5, 6, and 7 and ignoring terms of with low relative contribution, as detailed in (Iagnemma and Dubowsky, 2004), the parameters of interest are found in the expression shown in Equation 8, where terms $C 1, C 2$, and $C 4$ are calculated from the motion and loads on the wheel as presented in Equations 9, 10, and 11, where $A$ is calculated using Equation 12.

$$
\begin{gathered}
C 2 / C 4=c-\tan (\phi) C 1 / C 4 \\
C 1=A\left(\theta_{1}{ }^{2} W r+4 T \sin \left(\theta_{1}\right)-8 T \sin \left(1 / 2 \theta_{1}\right)\right) \\
C 2=4 T\left(\cos \left(\theta_{1}\right)-2 \cos \left(1 / 2 \theta_{1}\right)+1\right) \\
C 4=\theta_{1} r^{2} b\left(\cos \left(\theta_{1}\right)-2 \cos \left(\theta_{1} / 2\right)+2 A \cos \left(\theta_{1}\right)-4 A \cos \left(\theta_{1} / 2\right)+2 A+1\right) \\
A=1-\mathrm{e}^{-(r / k)\left(1 / 2 \theta_{1}+(1-s)\left(-\sin \left(\theta_{1}\right)+\sin \left(\theta_{1} / 2\right)\right)\right)}
\end{gathered}
$$

A linear least-squares regression can be conducted with Equation 8 to determine the maximum likelihood estimates of the coefficients $c$ and $\tan (\phi)$, with the assumption that the errors are normally distributed. The calculations of $C 1, C 2$, and $C 4$ rely on observations of $\theta_{1}, T, W, k$, and $s . T$ is measured with a torque transducer on the wheel axle, $s$ is calculated using the measurements of $\omega$ and $v, \theta_{1}$ is calculated from the sinkage $z$, and $W$ is calculated from the weight distribution of the robot. $k$ has been shown to have low variations and is taken as a constant (Iagnemma and Dubowsky, 2004).

\section{Development of a mobile robot for geotechnical ground surveys of oil sands tailings}

At the outset of the design process the functional specifications discussed in the previous section formed the design basis for the prototype rover RTC-I. The system was designed to take part in two trials: 1) Conduct a sample return mission: drive into deposit, drive to the sampling location, drill through the crust, reposition rover to take a sample, collect sample at depth, and drive back to shore (Fig. 8); and 2) Conduct a wheel-soil interaction study by traversing a patch of terrain (tailings sand around the deposit) and take measurements of the loads and state of a wheel to estimate soil parameters.

The following factors are taken into account in the general design of RTC-I: bearing strength of the treatment cell surface, thickness of crust, and depth of sample. In addition, the system needs to be ruggedized sufficiently to work in an open industrial environment, and to comply with safety, health, and environment (SHE) requirements of an industrial site.

The prototype comprises three main subsystems: a mobile platform, an auger drill, and a soft soil sampler (Fig. 9). The design of RTC-I allows it to traverse deposits with bearings strengths as low as $15 \mathrm{kPa}$, drill through crusts up to $45 \mathrm{~cm}$ thick, and sample up to $3 \mathrm{~m}$ deep. The characteristics of the field-ready platform vehicle are summarized in Table 1 . The following subsections present the design of the subsystems, focusing on solutions specific to meeting the functional specifications.

\subsection{Mobile platform}

Experience acquired while working with previous prototypes drove the selection of an electric platform for this study. A Clearpath Robotics Husky A200 UGV was modified to carry the payloads and instrumentation required for field experiments (Fig. 10a). A frame made of standard T-slotted aluminum framing was fixed to the chassis of the robot. This frame forms a high-stiffness and high-strength structure, into which reaction loads and vibrations can be transmitted during operation of the drill and sampler. The drill and sampler 


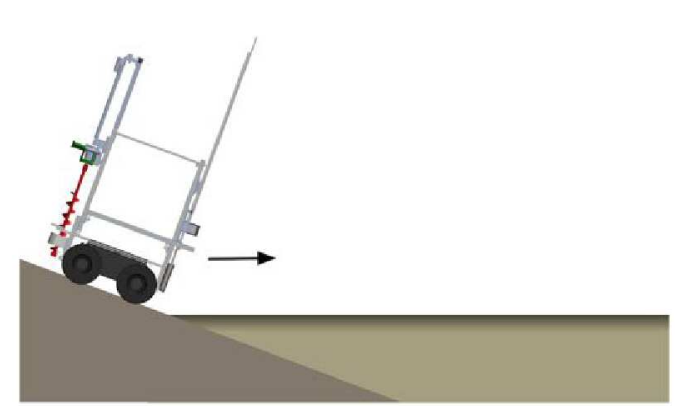

(a)

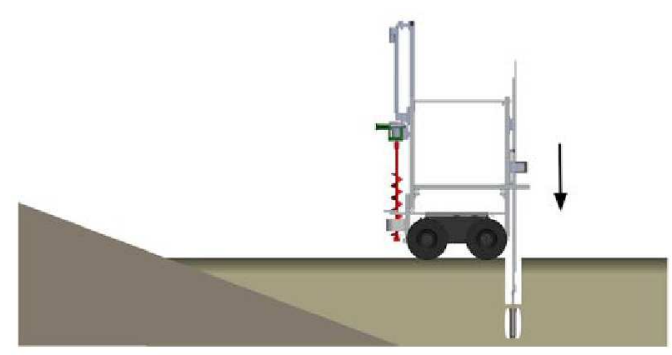

(c)

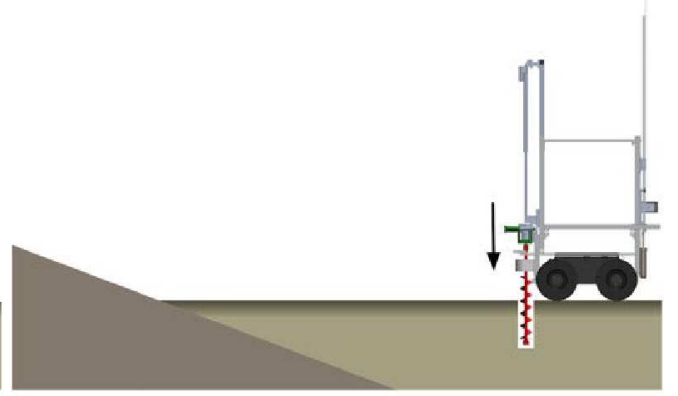

(b)

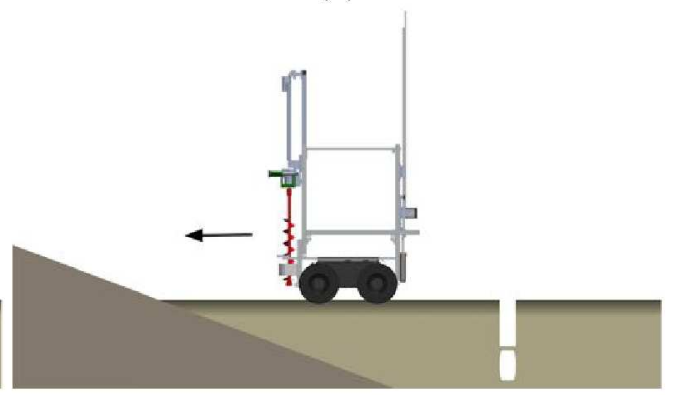

(d)

Figure 8: Tailings sample return mission: (a) RTC-I driving to the sampling location. (b) Rover drilling through the crust. (c) Rover collecting a sample at depth after repositioning. (d) Rover driving back to shore with sample.

mechanisms are mounted on the front and back of the frame to keep the centre of mass close to the centre of the vehicle. As built, the rover has mass of $123 \mathrm{~kg}$. A key design assumption is that the vehicle operates at slow speeds over a relatively flat terrain, except for the ramp to drive onto the deposit from the perimeter berm of the treatment cell. The rover is capable of a maximum climb grade of $28^{\circ}$ and has a roll-over angle of $35^{\circ}$. The position of the centre of gravity $(\mathrm{CG})$ and the static pitch-over and roll-over angles were found empirically.

The robot has two geared brushed DC Motors with rated continuous torques of $19.4 \mathrm{Nm}$. Each motor drives the wheels of one side of the rover using a belt and pulley transmission. The platform has a skid steering (differential drive) configuration, which was preferred over explicit steering due to its simplicity and because this configuration allows for quick changes in locomotion components, such as adding tracks. The platform does not have a suspension mechanism. The compliance of the pneumatic tires is sufficient to keep ground contact on the four wheels in the terrain of interest at target vehicle speeds. Previous studies have suggested that traditional spring-damper suspensions can lead to instabilities while conducting high vibrations operations such as drilling (Bartlett et al., 2008). Outriggers were considered to secure the mobile platform during drilling, but this was found to be an unnecessary addition.

Tracks were used to reduce the ground pressure of the robot (Fig. 10b). The rover requires low ground pressure to be able to traverse tailings with low bearing strengths. A ground pressure of $15 \mathrm{kPa}$ was achieved with the tracks. The tracks were designed to be easily removable in the field without having to remove wheel. In this way, wheel-soil interaction studies could be conducted with this platform without substantial modifications. The tracks were mounted by deflating the pneumatic tires and wrapping the tracks around them. They were secured by inflating the tires back to 20 psi. Initial laboratory testing demonstrated that several point turns on pavement were required for the tracks to show any misalignment with the tires. Additionally, the tracks were found to have sufficient flexibility to maintain ground contact over uneven terrain. No traction failures occurred, even when gravel was forced between the track and tires. 


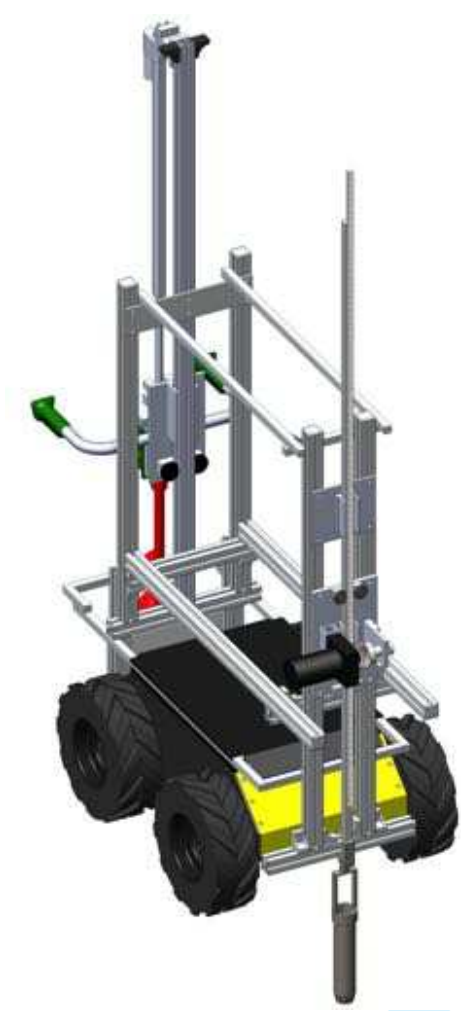

(a)

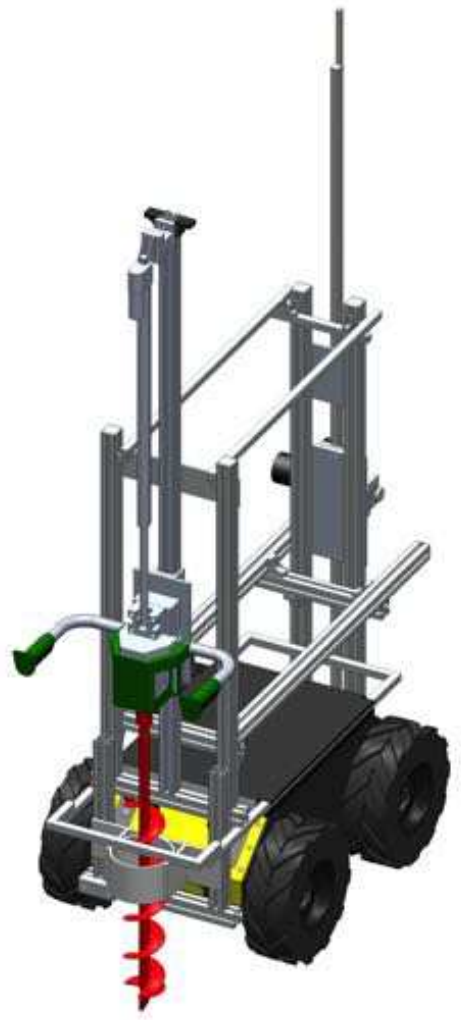

(b)

Figure 9: RTC-I with a soft soil sampler mounted on the front (a) and a drill on the back (b).

The main compartment in the chassis is used as an electronics bay to enclose the on-board computer, motor controllers, wireless connectivity modules, data acquisition units and batteries. These components are powered with a $24 \mathrm{~V} 20$ Ah sealed lead acid battery. A $12 \mathrm{~V} 10$ Ah lead acid battery is used to power other payloads. The power consumption levels and temperatures are monitored constantly during operation.

The front right wheel was instrumented for wheel-soil interaction studies. The torque on the axle of the wheel is measured with a wireless torque transducer composed of strain gauges in a Wheatstone bridge configuration mounted on an aluminum shaft, a signal amplifier and a wireless transceiver mounted in the wheel hub. The torque transducer was developed specifically for this application. An aluminum shaft was selected to provide sufficient strength and deformation over the operating range of the wheel. The signal amplifier was built to multiply the analog output signal of the Wheatstone bridge with a variable gain, which was fixed after initial operating range testing of the sensor. The amplified signal is sampled by a $2.4 \mathrm{GHz}$ module and transmitted to the robot. The wireless module, signal amplifier and bridge are powered by a rechargeable battery mounted on the hub of the wheel. The transducer was calibrated using a load cell and a lever arm. The digital output of the wireless module was recorded for different torques applied to the shaft over the operating range of the wheel.

In addition the torque on the axle, the contact angles of the wheel are estimated by measuring the sinkage of the wheel with infrared (IR) distance sensors. The wheel's angular and ground (linear) velocities are measured with off the shelf quadrature encoders and optical flow sensors. These measurements are used to estimate the cohesion stress and internal friction angle of the terrain. 
Table 1: RTC-I Specifications

\begin{tabular}{ll}
\hline Mass (with payloads) & $123 \mathrm{~kg}$ \\
Locomotion speed & $1 \mathrm{~m} \mathrm{~s}^{-1}$ \\
Wheel diameter & $330 \mathrm{~mm}$ \\
Ground clearance & $130 \mathrm{~mm}$ \\
Vehicle track & $556 \mathrm{~mm}$ \\
Vehicle wheel base & $513 \mathrm{~mm}$ \\
CG location from & $7 \mathrm{~mm}$ \\
vehicle track centre & \\
CG location from & $36 \mathrm{~mm}$ \\
$\quad$ wheel base centre & \\
CG height from wheel shaft & $400 \mathrm{~mm}$ \\
Static pitch-over angle & $28^{\circ}$ \\
Static roll-over angle & $35^{\circ}$ \\
Drill tower (upright) & $2060 \mathrm{~mm}$ \\
Sampler tower (upright) & $2570 \mathrm{~mm}$ \\
Runtime (heavy usage) & $2 \mathrm{hours}$ \\
\hline
\end{tabular}

\subsection{Drill}

A drilling mechanism was required to make a hole in the crust of the deposit so that the sampler can be lowered to the unconsolidated material. A brushless DC motor drives a $100 \mathrm{~mm}$ diameter auger as shown in Figure 10b. This modified commercial auger is powered by a $40 \mathrm{~V}$ lithium ion battery and has maximum speed of $180 \mathrm{rpm}$. The electric drill is mounted on a vertical linear actuator that can produce a maximum weight on bit (WOB) of $650 \mathrm{~N}$ and has a maximum extension of $60 \mathrm{~cm}$. Tests of this subsystem in a controlled setting by drilling into compacted turf soil were successful.

\subsection{Sampler}

A custom rack-and-pinion mechanism lowers a sample container through the unconsolidated material to collect samples (Fig. 3), driven by a high-power geared DC motor that moves a steel rack vertically on an aluminum extrusion supported by guide rails and linear bearings for T-slotted framing. The mechanism has a pull-push force of approximately $8800 \mathrm{~N}$. The rack has a usable length of approximately $1.9 \mathrm{~m}$, although extensions were built to extend the maximum depth of sampling to $3 \mathrm{~m}$.

A sample container with dimensions of $64 \mathrm{~mm}$ diameter and $127 \mathrm{~mm}$ length was fixed to one end of the rack with a custom bracket that allowed soft tailings to flow through the sampling container while it was open on both ends. One-way valves inside the bottom of the sample container allow soft material to move through the container as the rack is lowered. When the rack is lifted, the valves close and contain the material.

A GPS module is used to record the location where a sample is collected.

\subsection{Human-robot interaction and control systems}

The RTC-I is primarily controlled by teleoperation. Autonomous system monitoring, fault detection, and recovery routines have been incorporated to address issues when communication links fail or there are human-induced errors. At this point, the operator acts as the high level controller, task planner, and mission manager of the system. In the future, these subsystems can be automated. Automated discrete-event control has been demonstrated for most navigation functionality, and for payload operation, with human supervisor 


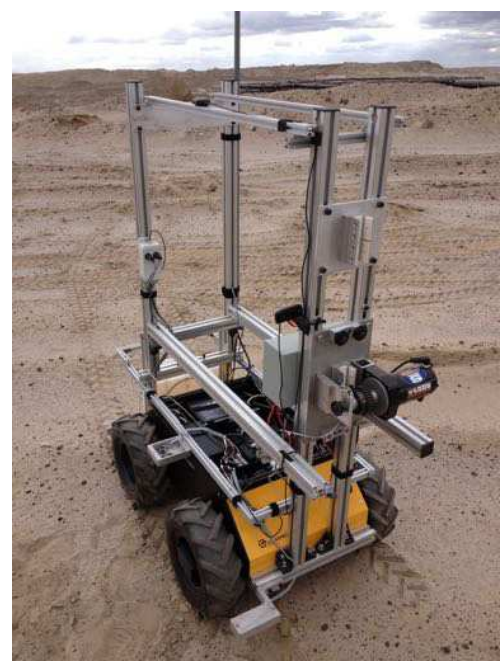

(a)

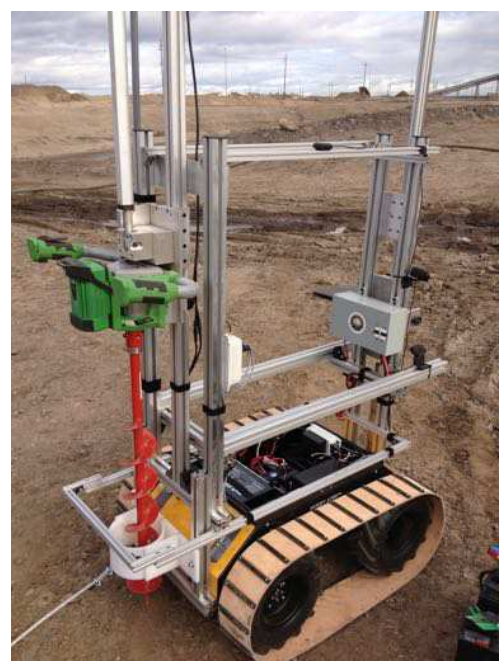

(b)

Figure 10: (a) RTC-I mobile platform. (b) RTC-I with tracks and drill in view.

override of autonomous control.

Reliable communication is critical for a robot working in environments that are not accessible to workers. Fault tolerance of the system is improved by implementing two separate communication links between the Operator Control Unit (OCU) and RTC-I. Wireless communication is suitable for this application because RTC-I operates in an open space and remains in line of sight of the operator. The primary communication link (PCL) is composed of a wireless local area network (WLAN) created by the on-board computer's $802.11 \mathrm{~g}$ wireless access point. The OCU computer connects to the network through a long range wireless client bridge. A high gain antenna was used to increase the communication range to over $150 \mathrm{~m}$.

The PCL transmits control commands and receives sensory feedback. The operator's control commands are gathered through a joystick and keyboard. These inputs are mapped to emergency-stop triggers, as well as speed, position, and on-off commands that are used by the mobile platform, drill, and sampler mechanisms. A system diagnostics module was integrated to monitor the status of the communication links and take action if a fault is discovered. If the PCL fails, a secondary communications link (SCL) relays basic motion commands. With this configuration, the user can maintain control of the robot unless there is a system-wide power failure.

The SCL consists of a remote control (RC) transmitter on the OCU and an RC receiver on the robot that has a range of over $1 \mathrm{~km}$. The $\mathrm{RC}$ transmitter inputs are used as velocity commands and emergency-stop triggers. Failsafe routines are required to ensure that the payloads are retracted from the ground if the PCL fails. Once the robot's payloads are secured, the operator can use the SCL to drive the robot back.

A steel cable was attached to the rover's chassis to be able to retrieve the robot in case that both communication links fail or if the robot's locomotion system malfunctions. The design did not allow for remote disconnection of the sampler or auger if they had already been deployed. This mission risk was accepted for proof-of-concept trials; but a commercial system would need to be able to jettison a stuck payload.

The software for the OCU and RTC-I was developed under the Robot Operating System (ROS) standard, which allows for a modular design methodology (Quigley et al., 2009). ROS software modules running on board the rover interact with data acquisition units and low-level control units. These modules receive control commands from the OCU through the ROS communication layers. Additionally, they transmit sensory feedback to assist the operator on the safe and effective control of the mobile platform and its 


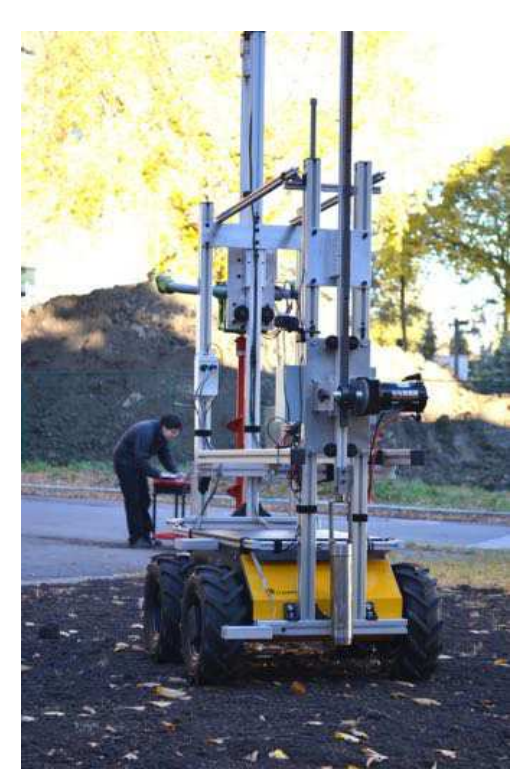

(a)

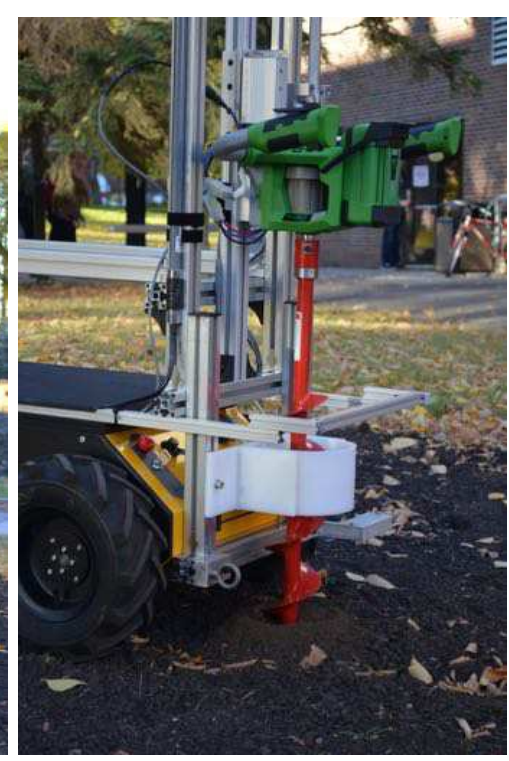

(b)

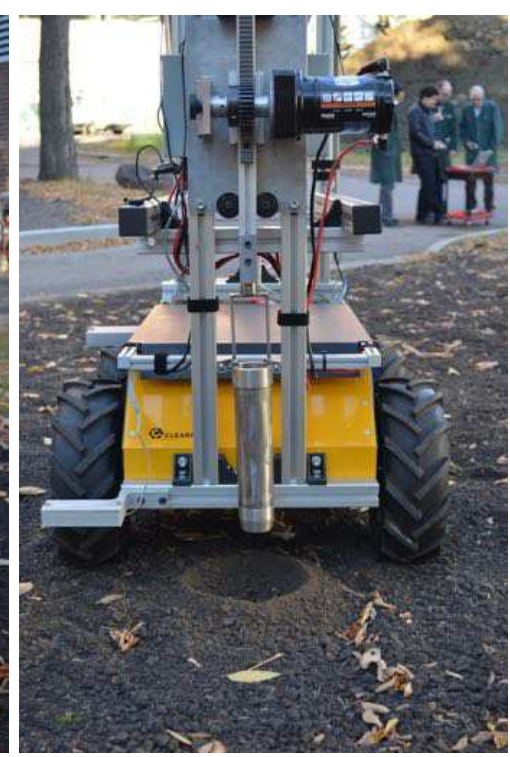

(c)

Figure 11: Outdoors testing of RTC-I: (a) Operator controlling the rover from a distance in a simulated sample return mission. (b) Teleoperating the drilling mechanism. (c) Repositioning the rover using visual feedback from the on-board cameras.

payloads. Two video cameras monitor the sample collection procedure. One camera points forward, to aid in navigation, while another camera points to the sampling mechanism so that the operator can reposition the mobile platform to align the sampler with the hole drilled through the crust. Other sensory feedback transmitted to the OCU includes the vertical position of the drill, WOB on the auger, battery voltage levels, and mobile platform status. Measurements gathered by the instrumented wheel are also transmitted. The ROS built-in recording tools log all sensory information.

Outdoor trials verified the performance and reliability of the human-robot interaction and control systems (Fig. 11). The experimental trials consisted of a simulated sample return mission: (1) an operator controls the robot from a distance to a predetermined sampling location, (2) the operator deploys the drill to make a hole, (3) repositions the rover to align the sampler to the hole using the visual feedback of the two onboard cameras only, and, (4) lowers the sampler to simulate sample collection. The operator was effective in controlling the robot throughout the simulated mission. It was noted that it is necessary to detect possible human-induced errors. We designed an ROS module to monitor the system state to detect command conflicts during operation. For example, the module prevents the operator from moving the robot while the drill or sampler are deployed. System state monitoring was implemented and verified before field testing.

\section{$5 \quad$ Field-Testing Experiments}

Field trials have been critical in determining the feasibility of introducing unmanned systems to industrial operations for environmental monitoring. This section presents several field-testing experiments that were conducted in October, 2013, at an oil sands operating plant near Fort McMurray, Alberta, Canada. This site contains several tailings treatment cells, both for experimental studies and for commercial production. The experimental cells are small deposits, holding approximately $2000 \mathrm{~m}^{2}$, dedicated to test consolidation processes. Production cells are on the order of 100 times larger and are part of tailings operations. The deposits are surrounded by berms made of tailings sand. 


\subsection{Safety and risk management and fail-safe demonstration}

Safety and risk management is an essential for introducing new technologies to industrial sites, such as UGVs to oil sands tailings sites. Throughout RTC-I's design process, FMEAs were used to address critical failure modes and improve the overall reliability of the robot. Redundant communication systems and a tether retrieval cable were identified as necessary to manage the effects of possible component failures; both improvements were implemented on the final design. Tether cables are impractical and may pose risks to the robot's stability when it's operating very far away from the shore. A tether cable was used in these field trials because the rover was not expected to travel further than 25 meters away from the shore of partially dried tailings deposits. Tether cables should not be used for long distance operations, instead rescue robots should be deployed to drag the rover back to shore if there is a failure. Rescue vehicles are typically used by tailings operators to retrieve trapped manned vehicles.

Safety training sessions were required for the robot operators before working on the field. A test plan was discussed with the mine operators and a Job Safety Analysis (JSA) was developed by the researchers and operations staff. Before starting any new experiment, a Field Level Risk Assessment (FLRA) was completed and the risks were controlled to acceptable levels.

On site, the rover was first tested to demonstrate the fail-safe systems to the mine operators. The rover was deployed on the sand dyke around the research cells. Mine operators identified the communication links as the components with highest risk of failure. The fault tolerance of the communication system was demonstrated by teleoperating the robot on the sand dyke and forcing the PCL to fail by disconnecting the wireless client bridge from the OCU computer. The broken link was detected by the robot's state monitoring system, triggering recovery routines. First, all actuators including payload and robot motors were stopped; then, any deployed tools were automatically retracted; and finally, the robot's control systems switched to the SCL and control of the mobile platform was maintained through the RC controller. A failure of the SCL was forced by switching the RC transmitter off. Once this failure was detected, all robot actuators were disconnected automatically to facilitate its retrieval using the tether cable. These tests demonstrated the redundancy of the rover's control channels and its fail-safe routines. The demonstrations were sufficient for the mine operators to consider the level of risk acceptable and to allow experiments to be conducted with RTC-I, provided that personnel were not in the area where the RTC-I was operating.

For this initial technology demonstration the mine operators preferred the robot to be teleoperated rather than to be navigated autonomously. Autonomous navigation to the platform is achievable using existing open-source ROS packages and will be demonstrated in future work.

\subsection{Surface characterization of dry tailings sand}

Surface characterization instrumentation and methods were tested on the tailings sand dyke surrounding the fluid tailings (Fig. 12). The robot was teleoperated over flat soft soil while collecting wheel loading and state measurements. The tether cable was not attached to the robot during these tests because the tailings sand had sufficient bearing strength to support the rover and workers without excessive sinkage.

Measurements were recorded for the wheel's angular speed $\omega$, ground speed $v$, sinkage $z$, and torque $T$. The front contact angle $\theta_{1}$ was estimated from the sinkage, and the slip ratio $s$ was calculated from $\omega, v$, and the wheel radius $r$, using Equation 4.

An example of the recorded measurements of the angular and ground speeds of the wheel is shown in Fig. 13a, with the corresponding slip ratios. The steady-state regions can be used for the parameter estimation algorithms that assume quasi-static motion. In this example, two regions of interest can be identified between the time ranges of $104 \mathrm{~s}$ to $106 \mathrm{~s}$ and 108 to $110 \mathrm{~s}$. The torques recorded during the test are shown in Figure $13 \mathrm{~b}$ and the sinkage and calculated contact angle on a region of interest are shown in Figure 13c. The results of the soil parameter estimations are discussed in Section 6.2. 


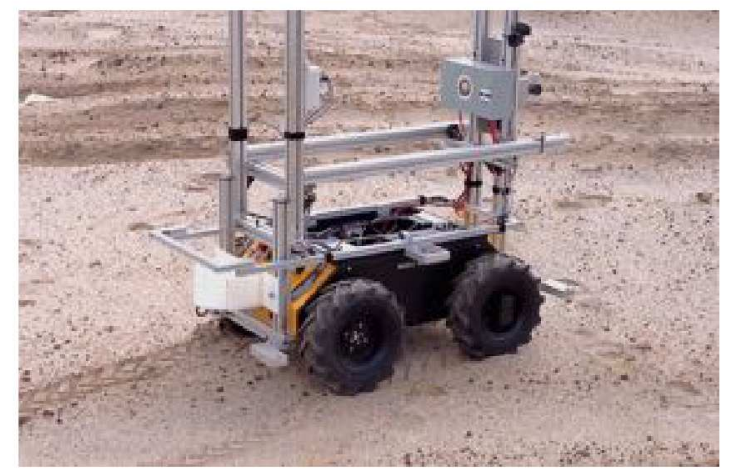

Figure 12: Field testing of RTC-I: Tailings sand surface characterization.

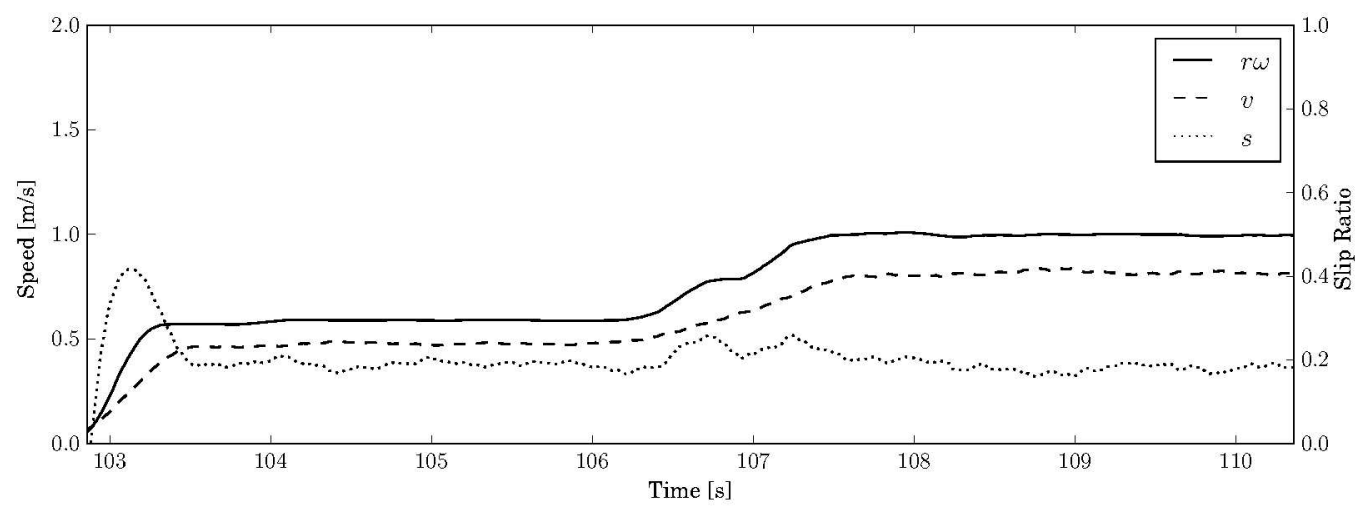

(a)

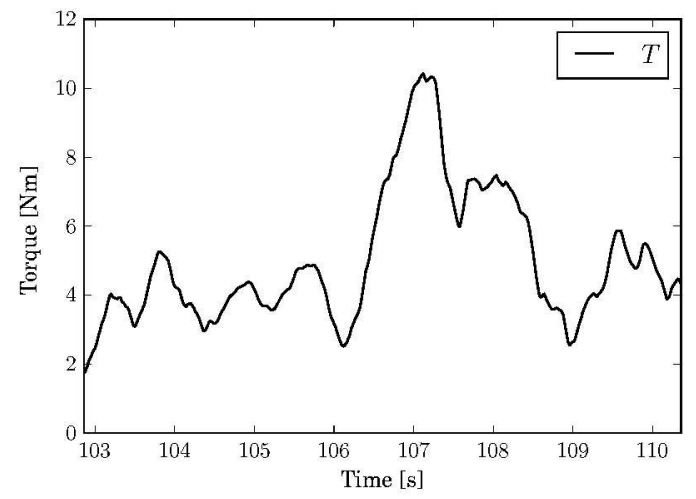

(b)

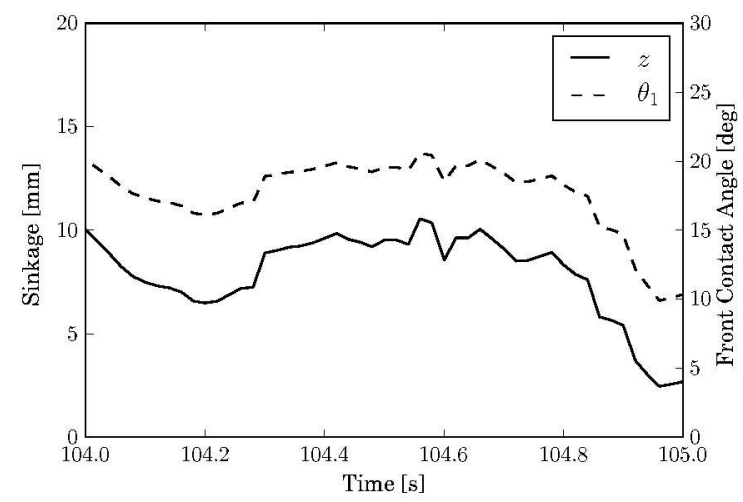

(c)

Figure 13: (a) Wheel speeds and slip ratio during sand surface characterization experiment, with measurements show two steady-state regions in this trial. (b) Wheel torque recorded during a surface characterization experiment. (c) Sinkage and calculated front contact angle recorded at steady-state motion.

\subsection{Subsurface sampling of partially dried tailings from tailings treatment cells}

Subsurface sampling experiments were carried out on three treatment cells. The first two trials were conducted on experimental cells, and the third trial was conducted on a large scale production cell. 


\subsubsection{Teleoperation on experimental tailings treatment cell with partially dried crust}

The rover was teleoperated into the deposit and positioned approximately 2 meters from the shore of the cell (Fig. 14a). Initially, the robot was teleoperated farther away from the shore, but the partially dried crust did not have sufficient bearing strength to support its weight. The auger was tested on the surface of the deposit up to a depth of $30 \mathrm{~cm}$ (Fig. 14b). Then, the robot was repositioned over the auger hole, and the sampling tool was lowered (Fig. 14c). It was found that the material under the crust at 2 meters from the shore was not sufficiently fluid to move through the sampling tool, and therefore no sample was collected. This motivated the subsequent sampling trial to be conducted on an cell with a high-strength dry crust that would support the weight of the robot further away from the shore.

The partially dried crust was pictured from the robot's camera view, as shown in Figure 14d. The dried mushroom-shaped structures can have high bearing strengths but the water-saturated cracks can cause the crust to fail easily and induce excessive sinkage of the platform. These instabilities may result in equipment getting stuck and limit manual sampling to floating docks.

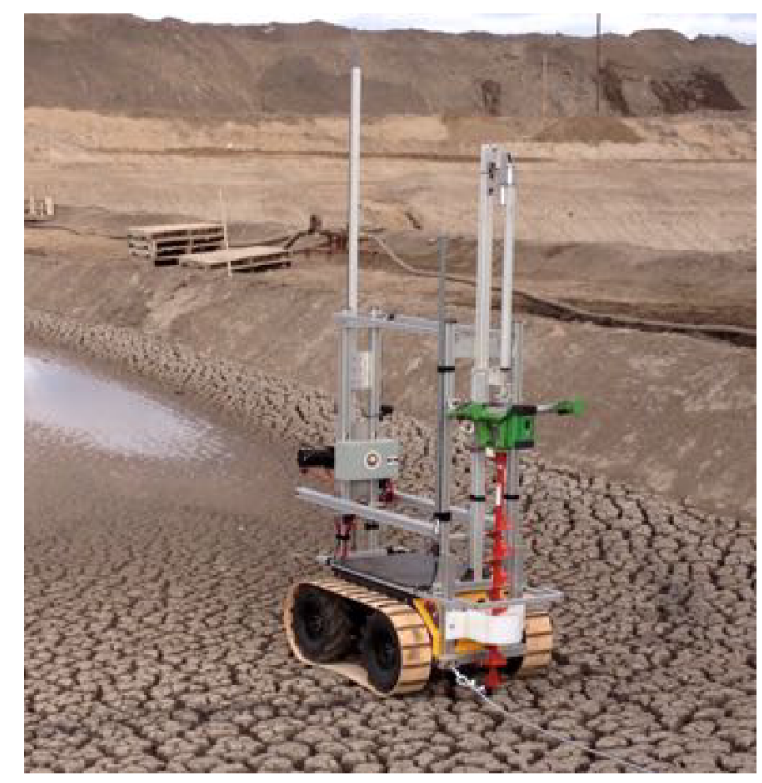

(a)

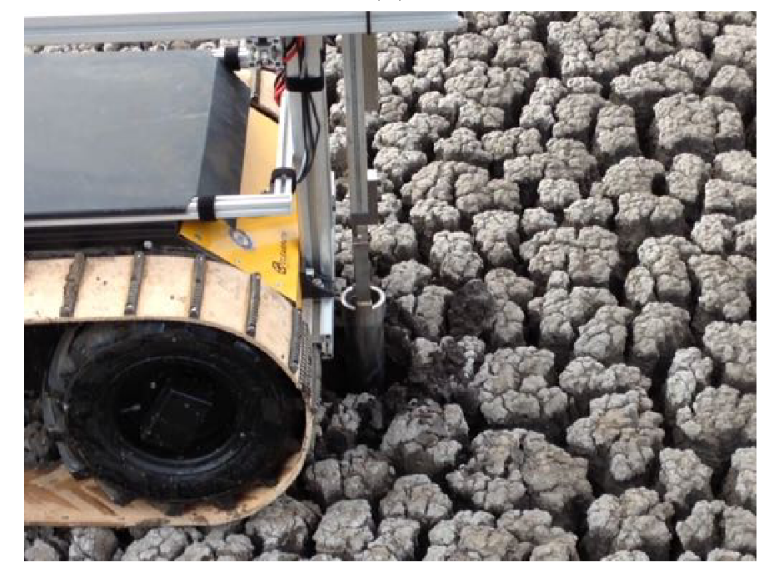

(c)

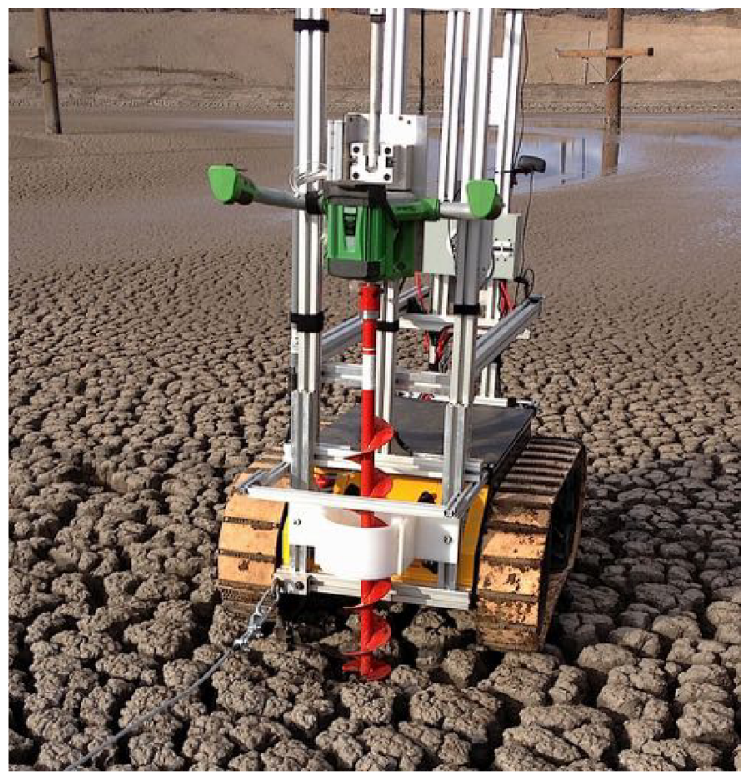

(b)

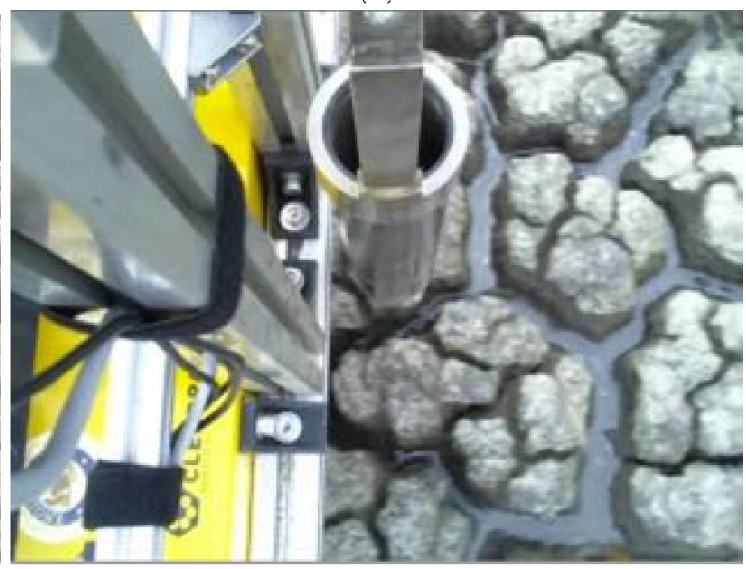

(d)

Figure 14: (a) RTC-I roving into an experimental cell. (b) Auger and drill subsystem test. (c) Sampler subsystem test. (d) On-board camera's view of the partially dried tailings surface. 


\subsubsection{Experimental cell with dry crust}

The robot was deployed on a deposit with high surface strength (Fig. 15a). The deposit had an estimated bearing strength of $60 \mathrm{kPa}$, which permitted the robot to drive a distance of 15 meters from the shore without any noticeable sinkage. The robot was positioned approximately $10 \mathrm{~m}$ from the shore of the deposit and the auger was lowered to make a hole $60 \mathrm{~cm}$ deep through the crust (Figure 15b). The robot was repositioned, the sampling tool was lowered, and a sample was collected at 1.7 meters depth (Fig. 15c). The rover was teleoperated back to the shore of the deposit and the sample was contained and stored (Fig. 15d).

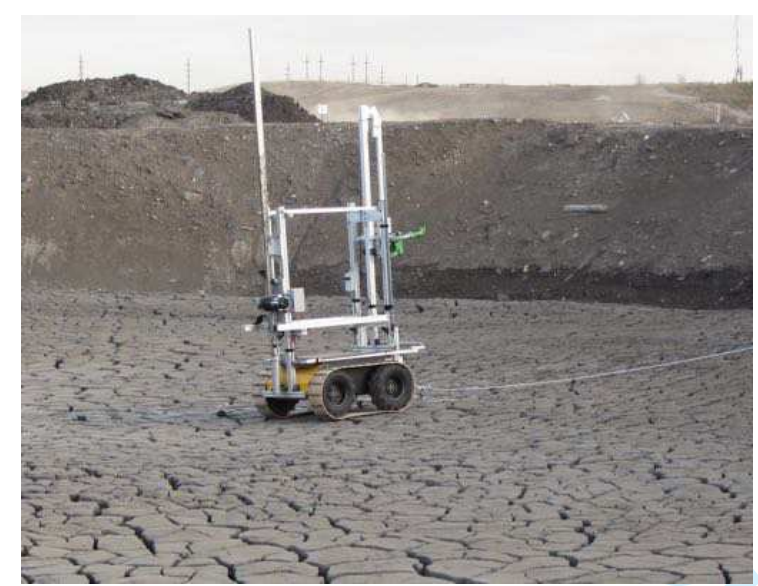

(a)

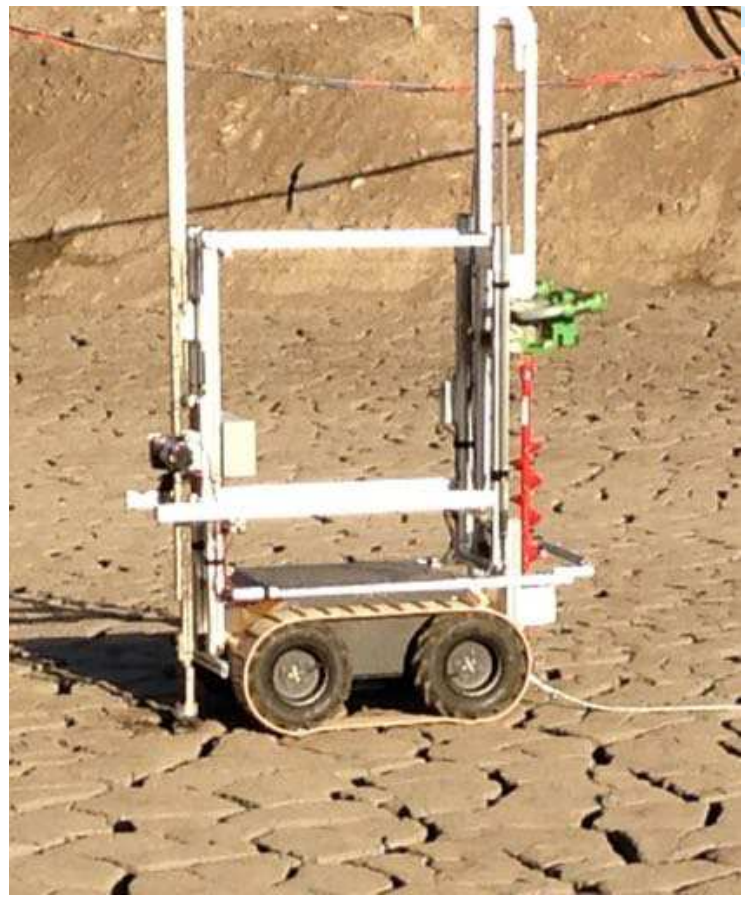

(c)

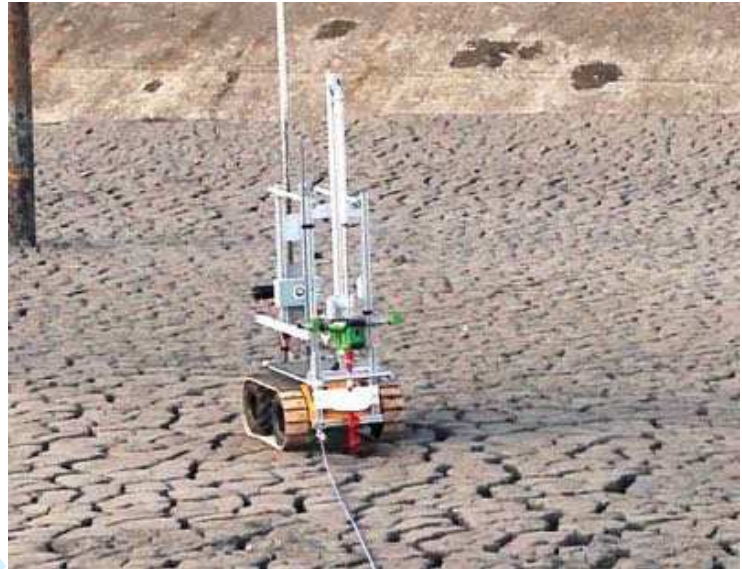

(b)

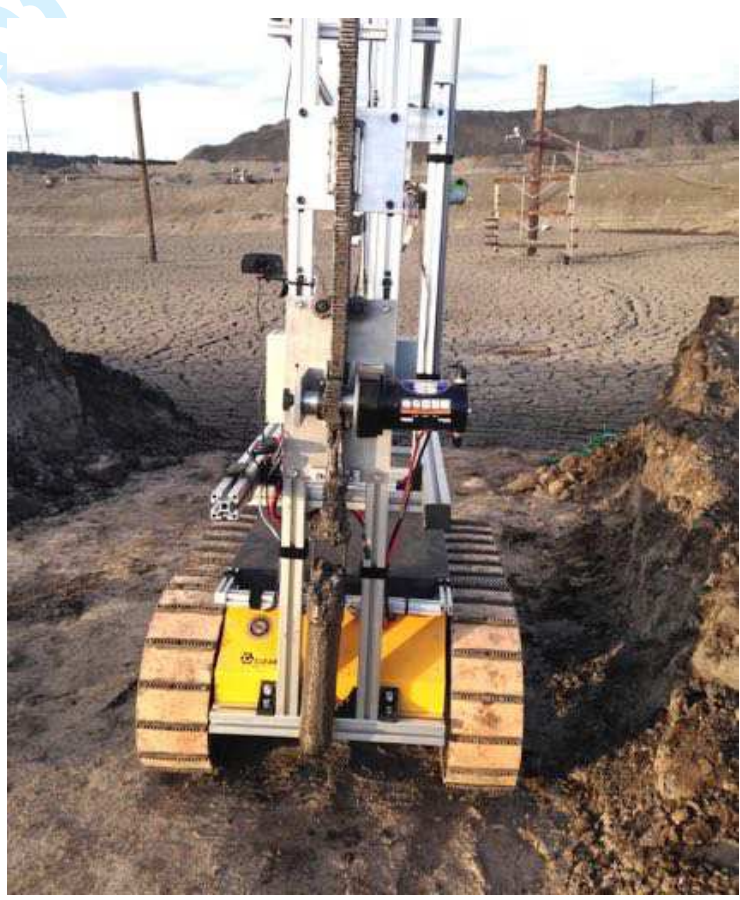

(d)

Figure 15: (a) RTC-I teleoperated into an experimental cell. (b) Drilling thought the crust. (c) Sampling tool lowered through the curst. (d) RTC-I with sample collected from $1.7 \mathrm{~m}$ depth. 


\subsubsection{Production cell}

A final sample retrieval trial was conducted on a production cell. The experiment was performed similarly to the previous trials. The rover was teleoperated down a soil ramp onto the surface of the cell, to approximately 15 meters from the shore (Fig. 16a). The deposit's crust was partially dried and supported the robot with minimal sinkage, although there was some general deflection of the surface. The rover successfully drilled through the crust (Figure 16b), repositioned, deployed the sampling tool to a depth of 1.5 meters and retrieved a sample (Figure17). The sampling process was monitored through the robot's on-board cameras as pictured in Figure 18.

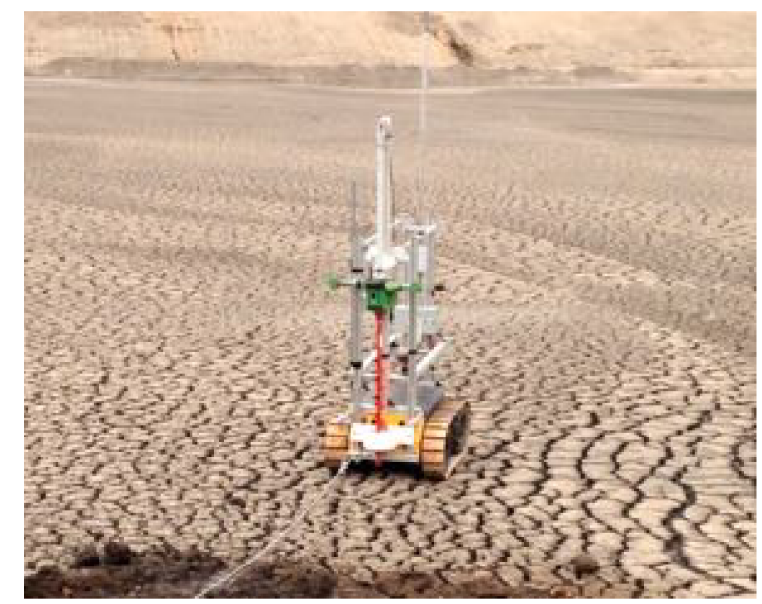

(a)

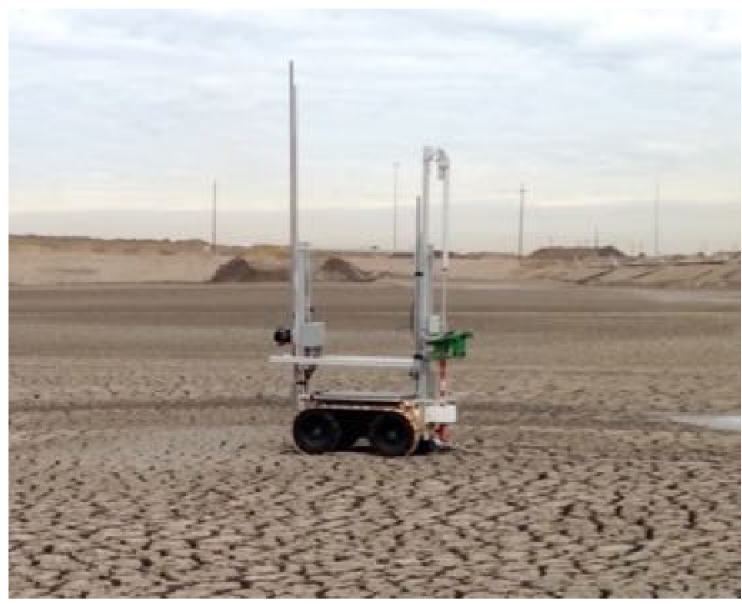

(b)

Figure 16: (a) RTC-I teleoperated into a production cell. (b) Drilling thought the crust.

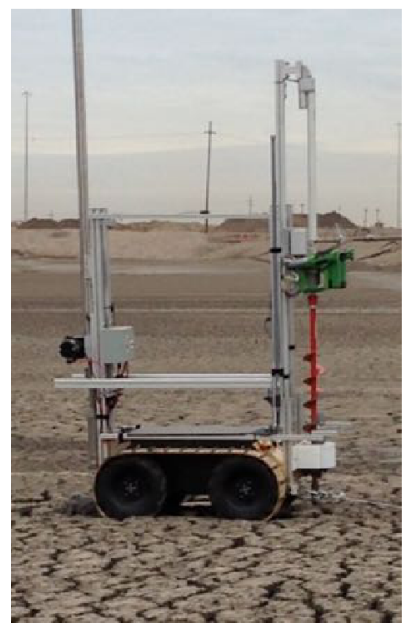

(a)

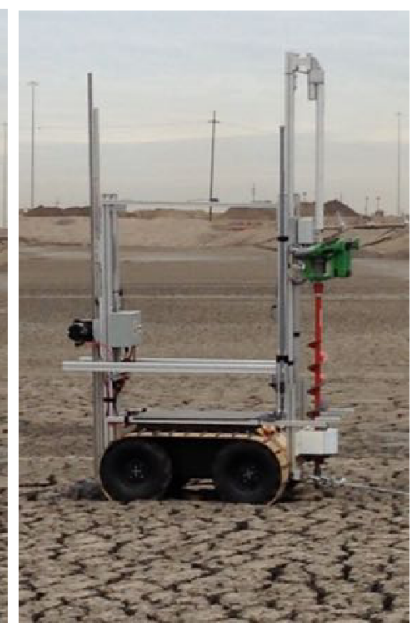

(b)

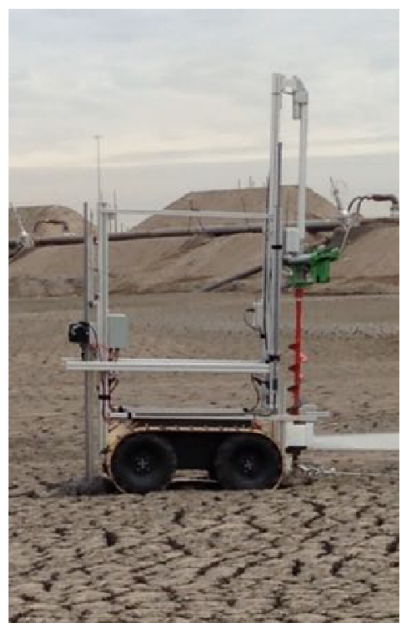

(c)

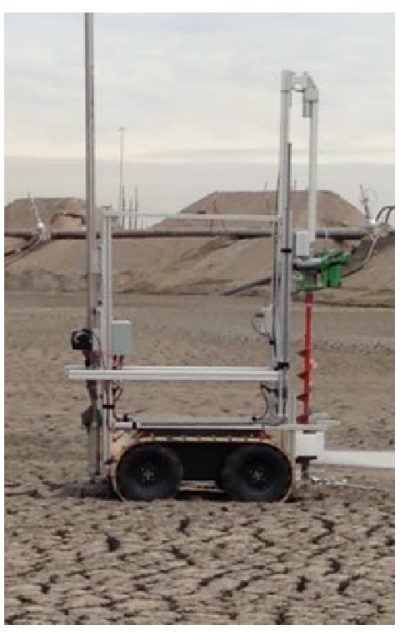

(d)

Figure 17: RTC-I lowering the sample container into the deposit to collect a sample. The sample container is pictured on the left side of each image. (a) RTC-I repositioned over the hole drilled through the deposit's crust. (b) RTC-I lowering sampling tool. (c) Sampling depth reached. (d) Sampling tool retracted with sample.

The sample qualitatively showed very little shear strength, indicating that rather than the cell acting as an elastic foundation, the crust was acting as a membrane to support the weight of the rover with shear strength at the surface crust only. 


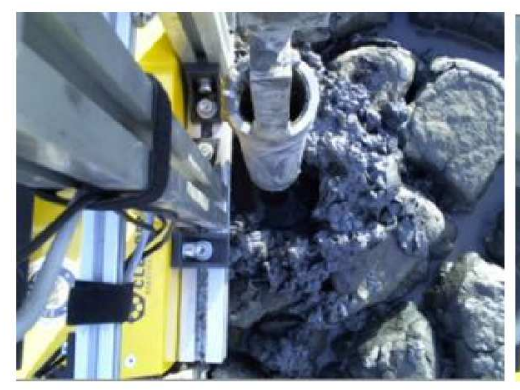

(a)

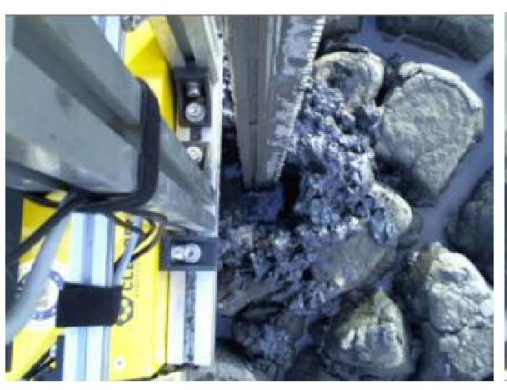

(b)

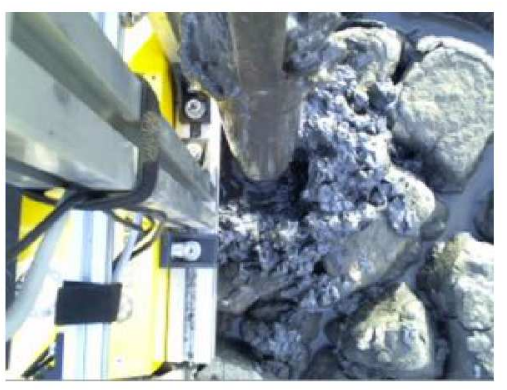

(c)

Figure 18: (a) Sampling tool repositioned over the drilled hole. (b) Sampling tool lowered through the crust to retrieve a sample. (c) Sampling tool retracted with sample.

\section{Surface \& Subsurface Characterization Results}

\subsection{Sample analysis}

The samples collected in the experimental and production cells were sent for analysis. For tailing characterization, typical analyses include bitumen content, particle size analysis, Methylene Blue Index (MBI), and solids content. These analyses were contracted to a laboratory that regularly studies tailings samples for the oil sands tailings operators. The results for the Dean \& Stark analysis and MBI analysis are presented in Table 2. It is noted that due to an unsecured seal, some moisture of the production cell sample evaporated before the analysis was conducted, and therefore the reported water content of the sample is less than a percentage by weight. The results of the Laser Diffraction Particle Size analysis are presented in Table 3. Both samples have similar particle size distributions (Figure 19).

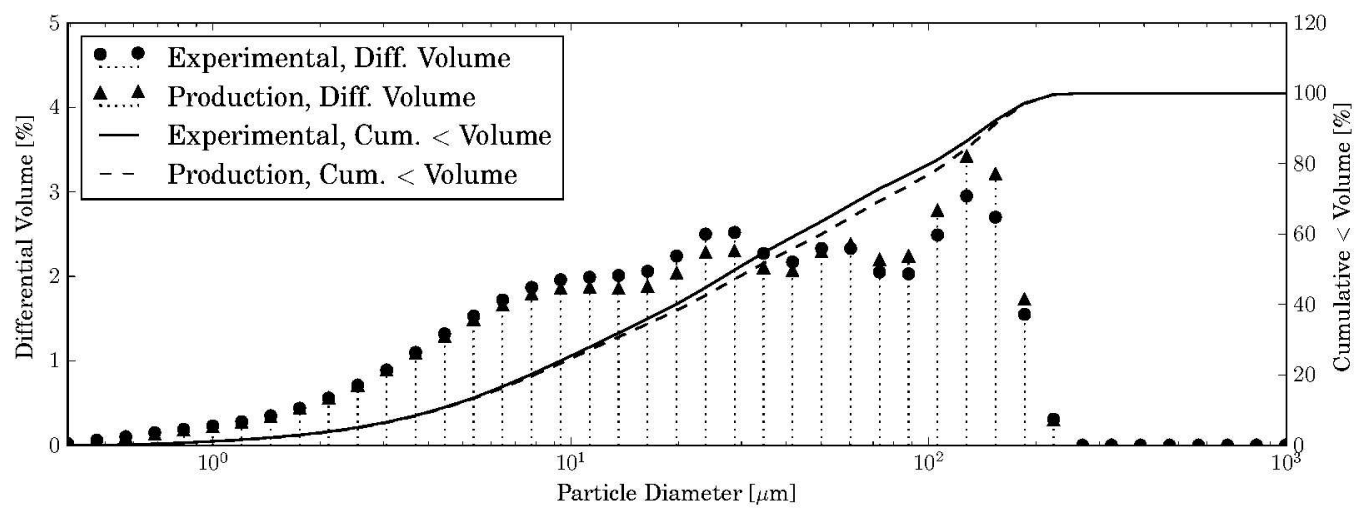

Figure 19: Particle size distributions of the samples collected.

Table 2: Dean Stark Analysis and Methylene Blue Index (MBI) Report

\begin{tabular}{|l|cccccccc|}
\hline Sample & $\begin{array}{c}\text { Weight } \\
{[\mathrm{g}]}\end{array}$ & $\begin{array}{c}\text { Bitumen } \\
{[\mathrm{g}]}\end{array}$ & $\begin{array}{c}\text { Mineral } \\
{[\mathrm{g}]}\end{array}$ & $\begin{array}{c}\text { Water } \\
{[\mathrm{g}]}\end{array}$ & $\begin{array}{c}\text { Bitumen } \\
\%\end{array}$ & $\begin{array}{c}\text { Mineral } \\
\%\end{array}$ & $\begin{array}{c}\text { Water } \\
\%\end{array}$ & $\begin{array}{c}\text { MBI } \\
{[\mathrm{meq} / 100 \mathrm{~g}]}\end{array}$ \\
\hline Experimental Cell & 134.81 & 10.47 & 78.68 & 45.66 & 7.77 & 58.36 & 33.87 & 5.81 \\
Production Cell & 90.43 & 7.61 & 82.22 & 0.60 & 8.42 & 90.92 & 0.66 & 6.02 \\
\hline
\end{tabular}


Table 3: Laser Diffraction Particle Size Analysis

\begin{tabular}{|l|cccccccccc|}
\hline \multicolumn{1}{|c|}{ Sample } & \multicolumn{1}{c|}{ Particle Diameter Size $[\mu \mathrm{m}]$} \\
& Mean & Median & Mode & $\mathrm{d} 5$ & $\mathrm{~d} 10$ & $\mathrm{~d} 25$ & $\mathrm{~d} 50$ & $\mathrm{~d} 75$ & $\mathrm{~d} 90$ & $\mathrm{~d} 95$ \\
\hline Experimental Cell & 50.00 & 27.58 & 127.7 & 2.40 & 4.00 & 9.39 & 27.58 & 76.73 & 136.60 & 161.10 \\
Production Cell & 53.83 & 30.78 & 140.1 & 2.44 & 4.06 & 9.72 & 30.78 & 88.50 & 142.10 & 164.50 \\
\hline
\end{tabular}

\subsection{Terrain parameters estimation}

The cohesive stress and internal friction angle of tailings sand can be estimated from the wheel-soil interaction observations during the surface characterization experiments. These parameters can aid in understanding the trafficability of the terrain as described in Section 3.2.

This section discusses the parameter estimation results obtained from the field trials.

\subsubsection{Tailings sand parameter estimation results}

The cohesion stress and internal friction angle of the terrain were estimated recursively from the on-board measurements collected during the field trials. As described in Section 5.2, measurements of $z, \omega, v$, and $T$ were obtained during the surface characterization experiments. A least-squares regression was used with Equation 8 to obtain $\hat{c}$ and $\hat{\beta}$, the estimates of $c$ and $\tan (\phi)$ respectively. Only measurements of steady-state operation were included in the parameter estimation analysis.

The regression results for $\hat{c}$ and $\hat{\beta}$ are presented in Table 4. The P-value of the the two-sided test for $\hat{c}$ is higher than 0.05, therefore the analysis fails to reject the null hypothesis: $H_{0}: c=0[\mathrm{~Pa}]$, for a $95 \%$ confidence level. This result is expected for cohesionless soils such as dry sand. The estimates obtained recursively show that after approximately 140 observations, the estimates do not vary significantly (Fig. 20a and 20b).

The results of the regression analysis assuming cohesionless soil are presented in Table 5 . The coefficient of determination for this analysis was calculated to be: $R^{2}=0.974$. The $95 \%$ confidence intervals of $\hat{\beta}$ correspond to an estimate of the internal friction angle, $\hat{\phi}=33.64 \pm 0.63$, which is similar to the values obtained from shear failure experiments of washed dry sand reported in literature, $c=0.65 \pm 0.24 \mathrm{kPa}$ and $\phi=32.1 \pm 2.82 \mathrm{deg}$ (Iagnemma and Dubowsky, 2004). It is expected that different types of sand will have moderate variations in their soil parameters because these are affected by many factors including moisture content, particle size distribution, and particle angularity.

Estimation errors are expected due to the linearization assumptions and further simplifications of the linearized terramechanics model. Additionally, sensor noise and error in the assumed value of the shear displacement under the wheel contribute to the overall error of the estimation. The experiments were conducted on an uncontrolled terrain around the tailings deposit, therefore, it is possible that deviations existed on the homogeneous and isotropic characteristics assumed for the terrain.

Table 4: Regression Results

\begin{tabular}{|l|rrccc|}
\hline & Est. & Std. Error & $95.0 \%$ Conf. Int. & $\mathrm{t}$ & $\mathrm{P}>|\mathrm{t}|$ \\
\hline$\hat{c}[\mathrm{~Pa}]$ & 940.426 & 2555.953 & $-4101.782,5982.634$ & 0.368 & 0.713 \\
$\hat{\beta}$ & 0.599 & 0.180 & $0.244,0.954$ & 3.327 & 0.001 \\
\hline
\end{tabular}




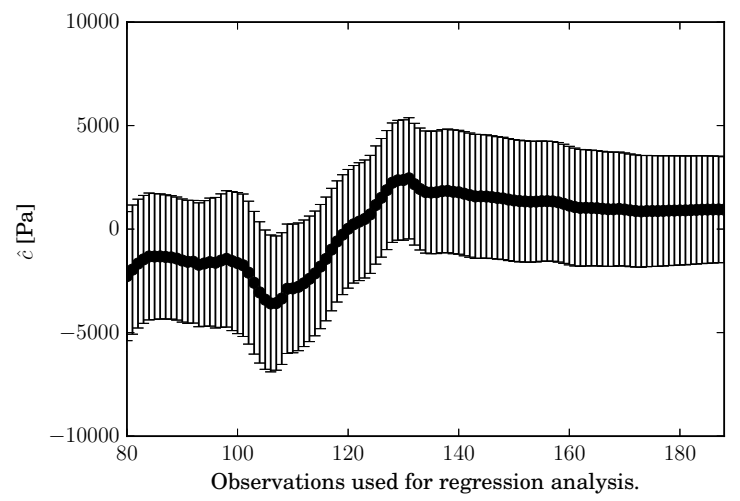

(a)

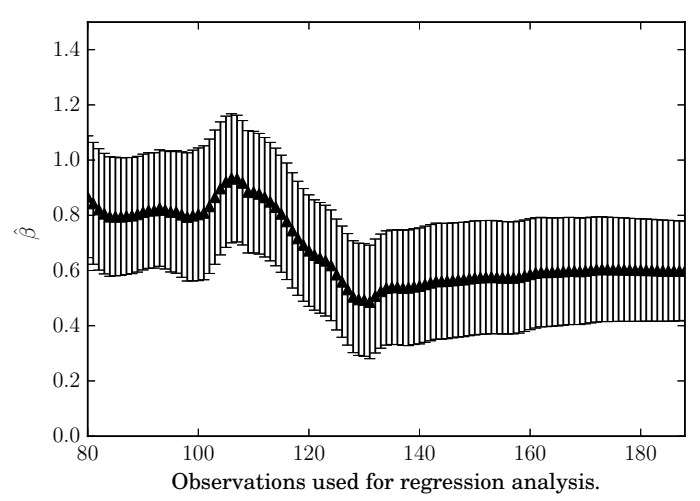

(b)

Figure 20: (a) Recursive estimation results for $\hat{c}$ (a) and $\hat{\beta}$ (b). Error bars show standard error of the estimates.

Table 5: Regression Results For Cohessionless Soil

\begin{tabular}{|r|rrccc|}
\hline & Est. & Std. Error & $95.0 \%$ Conf. Int. & $\mathrm{t}$ & $\mathrm{P}>|\mathrm{t}|$ \\
\hline$\hat{\beta}$ & 0.665 & 0.008 & $0.650,0.681$ & 83.758 & 0.000 \\
\hline
\end{tabular}

\section{Lessons Learned and Future Work}

The results of the field trials indicate that surface and subsurface characterization of oil sands tailings is technically feasible. Sampling and surface characterization have been demonstrated with RTC-I but still several improvement areas have been identified.

A limitation of the current system is that the instrumentation required to collect measurements for the terrain parameter estimation algorithms is coupled to the propulsion mechanism of the robot. While wheels are all right for terrain with good bearing strength, that circumstance may not always be the case with soft tailings deposits. A wheeled platform is generally not suitable to traverse water-saturated terrains, especially in low-bearing strength deposits. Balloon tires can be used, but tracked vehicles and amphibious vehicles are preferred for these applications. In the current design, the terrain parameter estimations can only be conducted when wheels are being used, limiting the terrain surfaces that can be characterized. A separate payload for wheel-soil interaction force estimation is required. This payload would consist of an actuated wheel that is pressed onto the terrain with variable normal forces, while collecting measurements similarly as the instrumented wheel used in RTC-I. The payload can be integrated into other ground vehicles as part of a collection of instruments to characterize very soft deposits. Spatial verification of the estimated soil parameters can be obtained by integrating standard geotechnical tools for cone-penetrometer and a vane shear testing.

Two limitations were found on the sampling subsystem of RTC-I. First, the sampling mechanism is currently limited to a single sample per trip, which is not desirable when working on large deposits where a large number of samples is required. The subsurface characterization of a deposit can be conducted faster if a sample magazine were added to the rover to collect and store more samples. A design has been created for a magazine that can collect and carry twelve samples. On very large deposits higher sample capacities and multiple unmanned systems may be required. Second, an improvement in the sample collection mechanism is required to minimize the risk of hard material obstructing the sample container as it is lowered through the deposit. The one-way valves of the sample container can be replaced with an actuated mechanism to open and close the container. The closed container can be moved through hard material and be opened 
to capture material only at the desired sampling depth, reducing the uncertainty of the depth where the material was captured and minimize cross-contamination between material from different depths.

Additional instrumentation and payloads can be mounted on the rover for in-situ analysis. In future field trials, a hyper-spectral imaging camera and data acquisition system mounted on the rover will be used to detect different clay types, quantify material composition, assess hydrocarbon abundance, and to create moisture content maps.

Near-term developments will focus on implementing the improvements discussed, as well as adding different levels of autonomy to the system. Initially, the drilling and sampling subsystems can be automated to operate with minimal human supervision. Further developments can lead to full autonomy of the system, with on-board task planning and mission managing. Possible long-term work will focus on adding cooperation between several unmanned systems, including aerial vehicles that could conduct surveys to identify regions of interest for ground vehicles to explore, and any zones that would not be navigable.

The technologies developed through this work can be used for environmental monitoring of other types of mine tailings, and can be further extended to other applications, such as robotic systems working on agricultural land, on glaciers, and on permafrost.

\section{Conclusions}

The development and field experimentation trials of RTC-I, a rover for tailings characterization, have been described. The design of RTC-I focused on meeting the functional specifications for characterizing soft oil sands tailings. The rover was uniquely configured to estimate terrain parameters while traversing deformable terrain, and capture a subsurface sample from the tailings deposit. The different subsystems of the field-ready prototype have been described. Building and field testing RTC-I has demonstrated that robotic systems can aid in environmental monitoring of potentially hazardous industrial sites, such as a treated tailings impoundment. Field demonstrations have established the concept of collecting samples from tailings deposits, as well as the capability to estimate cohesive stress and internal friction angle of tailings sand. The favourable results of the field trials show that the technologies proposed are suitable for tailings characterization. Limitations of the demonstrated system have led to a set of possible improvements; and future work has been outlined with the intent to develop and implement robotic systems with geotechnical tools to aid in the environmental monitoring of industrial sites and other challenging soil types.

\section{Acknowledgments}

Financial support is gratefully acknowledged from the Natural Sciences and Engineering Research Council of Canada (NSERC) and the University of Alberta. The authors wish to thank the Mechanical Engineering Machine Shop staff for their technical support and specially Rick Bubenko, Andrew Campbell, Rick Conrad, Roger Marchand, and Dave Waege for their collaborations in system concept and integration. Logistical support from the oil sands company operations staff is also much appreciated.

\section{References}

Alberta-Energy (2014a). Oil sands. http://www.energy.alberta.ca/OurBusiness/oilsands.asp.

Alberta-Energy (2014b). Oilsands 101: Reclamation. http://www.energy.alberta.ca/OilSands/1722.asp.

Alberta-Energy (2014c). Oilsands 101: Resource. http://www.energy.alberta.ca/OilSands/1715.asp.

Alberta-Energy-Regulator (2009). Directive 074: Tailings performance criteria and requirements for oil sands mining schemes. http://www.aer.ca/rules-and-regulations/directives/directive-074. 
Alberta-Energy-Regulator (2010). Ercb conditionally approves tailings plans for shell muskeg river project. http://www.aer.ca/about-aer/media-centre/news-releases/news-release-2010-09-20-nr2010-13.

Allen, E. W. (2008). Process water treatment in canada's oil sands industry: I. target pollutants and treatment objectives. Journal of Environmental Engineering and Science, 7(2):123-138.

Anderson, R., Jandura, L., Okon, A., Sunshine, D., Roumeliotis, C., Beegle, L., Hurowitz, J., Kennedy, B., Limonadi, D., McCloskey, S., Robinson, M., Seybold, C., and Brown, K. (2012). Collecting samples in gale crater, mars; an overview of the mars science laboratory sample acquisition, sample processing and handling system. Space Science Reviews, 170(1-4):57-75.

Bartlett, P., Wettergreen, D., and Whittaker, W. R. L. (2008). Design of the scarab rover for mobility and drilling in the lunar cold traps. In International Symposium on Artificial Intelligence, Robotics and Automation in Space.

Beier, N., Wilson, W., Dunmola, A., and Sego, D. (2013). Impact of flocculation-based dewatering on the shear strength of oil sands fine tailings. Canadian Geotechnical Journal, 50(9):1001-1007.

Bekker, M. G. (1969). Introduction to Terrain-Vehicle Systems. University of Michigan Press, Michigan.

Dusseault, M. B. and Don Scott, J. (1983). Tailings pond behavior and characterization of oil sand tailings sludge. Particulate Science and Technology, 1(3):295-309.

Freitas, G., Lizarralde, F., Hsu, L., Paranhos, V., dos Reis, N. R. S., and Bergerman, M. (2011). Design, modeling, and control of a wheel-legged locomotion system for the environmental hybrid robot. In Proceedings of the IASTED International Conference, number CMU-RI-TR-.

Helmick, D., McCloskey, S., Okon, A., Carsten, J., Kim, W., and Leger, C. (2013). Mars science laboratory algorithms and flight software for autonomously drilling rocks. Journal of Field Robotics, 30(6):847-874.

Iagnemma, K. and Dubowsky, S. (2004). Mobile Robots in Rough Terrain Estimation, Motion Planning, and Control with Application to Planetary Rovers, volume 12 of Springer Tracts in Advanced Robotics. Springer Berlin / Heidelberg.

Iagnemma, K., Shibly, H., and Dubowsky, S. (2002). On-line terrain parameter estimation for planetary rovers. Robotics and Automation, 2002. Proceedings. ICRA '02. IEEE International Conference on, $3: 3142-3147$.

Lipsett, M. and Dwyer, S. (2009). A robotic system to characterize soft tailings deposits. In Proceedings of Mine and Tailings Waste Conference 2009, Banff Alberta.

Lipsett, M., Yuen, J., Olmedo, N., and Dwyer, S. (2014). Condition monitoring of remote industrial installations using robotic systems. In Lee, J., Ni, J., Sarangapani, J., and Mathew, J., editors, Engineering Asset Management 2011, Lecture Notes in Mechanical Engineering, pages 231-241. Springer London.

Matthews, J., Shaw, W., MacKinnon, M., and Cuddy, R. (2002). Development of composite tailings technology at syncrude. International Journal of Surface Mining, Reclamation and Environment, 16(1):24-39.

Olmedo, N. and Lipsett, M. (2012). Oilsands tailings characterization using a robotic system. In Zacny, K., editor, Earth and Space 2012, pages 1167-1176. American Society of Civil Engineers.

Quigley, M., Conley, K., Gerkey, B. P., Faust, J., Foote, T., Leibs, J., Wheeler, R., and Ng, A. Y. (2009). Ros: an open-source robot operating system. In ICRA Workshop on Open Source Software.

Wettergreen, D., Moreland, S. J., Skonieczny, K., Jonak, D., Kohanbash, D., and Teza, J. (2010). Design and field experimentation of a prototype lunar prospector. International Journal of Robotics Research, 29(12):1550 - 1564 .

Yoshida, K. (2006). Terramechanics-based analysis and traction control of a lunar/planetary rover. Field and Service Robotics, 24:225-234. 
Zhou, F., Arvidson, R. E., Bennett, K., Trease, B., Lindemann, R., Bellutta, P., Iagnemma, K., and Senatore, C. (2014). Simulations of mars rover traverses. Journal of Field Robotics, 31(1):141-160. 